\title{
A High Tech Start-up's Journey Towards Funding
}

\author{
By Anna Samoylova
}

A thesis

submitted to the Victoria University of Wellington

in fulfilment of the requirements for the degree of

'Masters in Advanced Technology Enterprise' 


\section{Acknowledgments:}

I would like to express my deepest appreciation to a number of people who have hugely contributed to the successful completion of both my individual thesis and the work which my start up team and I did towards creating value to our start-up 'Auti'.

My supervisor, Professor David Crick from the School of Marketing and International Business. David's enthusiasm into research, the way he passionately discussed research topics made my research much more interesting, he opened my mind to look into things I would otherwise have missed. Most importantly his constant support and advice not only shaped the core of my thesis but also shaped me into a true academic.

Programme director Doctor Paul Smith. His positive energy and optimistic view on things are characteristics which are critical to running a course such as 'Masters in Advanced Technology enterprise' which looks at creating new high tech products. The combination of having to create a new technology and commercialising a product guaranteed stressful days and tears ahead. No matter what difficulties my team or I faced Paul always helped find a solution.

Kate McGrath, from the School of 'Chemical and Physical Sciences. Kate is the main person behind the creation of the Masters programme. Thank you for creating a platform where young entrepreneurs can open their minds and are given the opportunity to create. Innovation is the future, I hope one day to make an innovative stamp to this world, making a positive change. This programme has given me the skills, knowledge and confidence which undoubtedly helped towards achieving this goal.

Helen Andreae the project champion of 'Auti'. It was a great experience working with you.

Michael Elwood Smith who offered his time to be a mentor to all teams in the master's programme was a huge contributor to the success of all teams.Thank you Michael.

Last but not least thank you to everyone who makes 'Victoria University of Wellington' the amazing University that it is. I have truly enjoyed my time at 'Victoria'. It has been a privilege meeting everyone, including academic staff and students. My time at 'Victoria' has been a once in a life time experience which I will treasure forever. 
Page 2 of 97

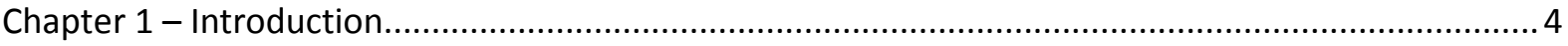

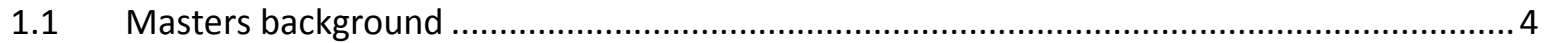

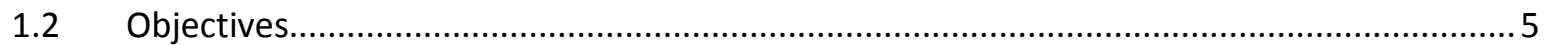

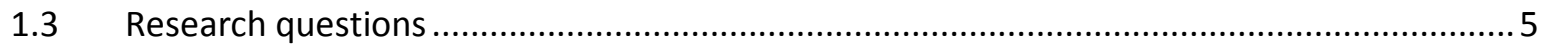

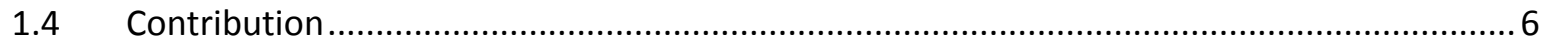

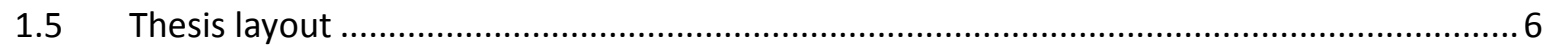

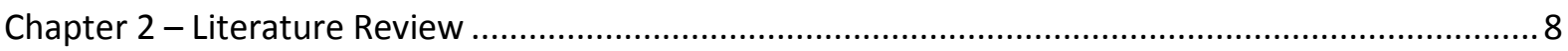

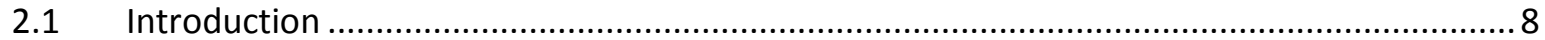

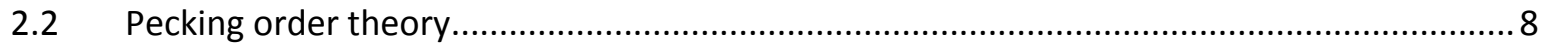

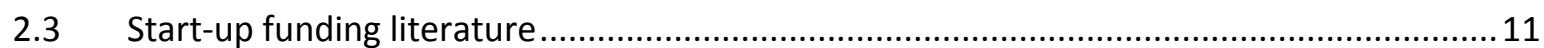

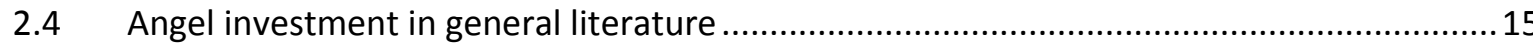

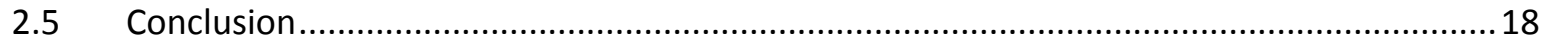

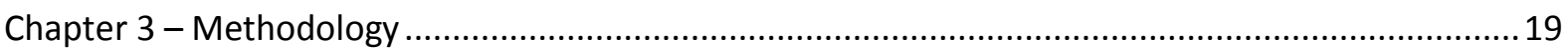

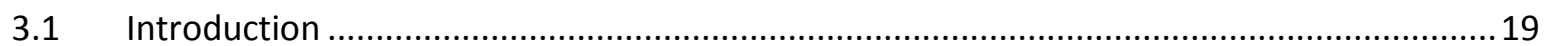

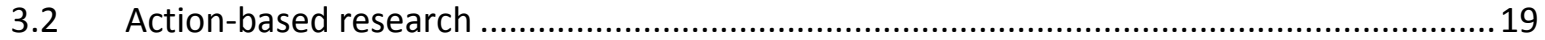

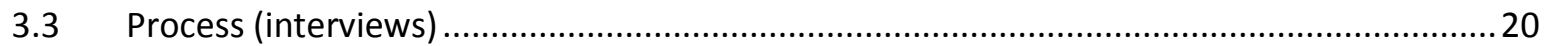

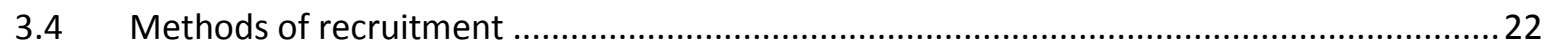

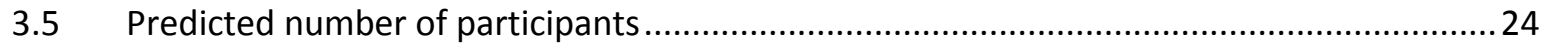

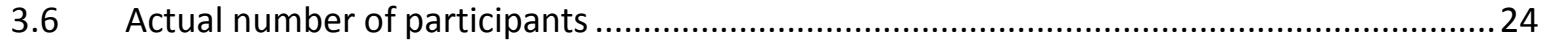

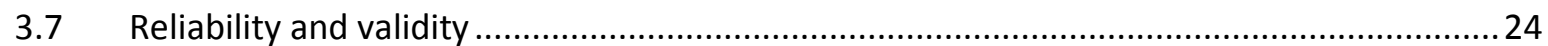

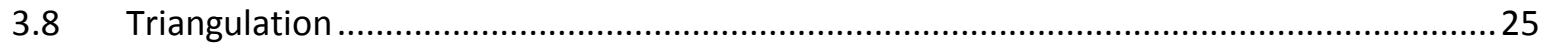

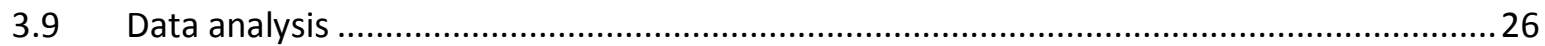

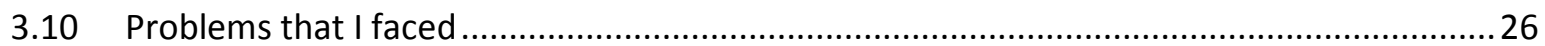

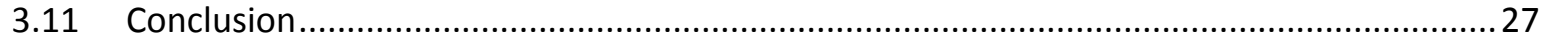

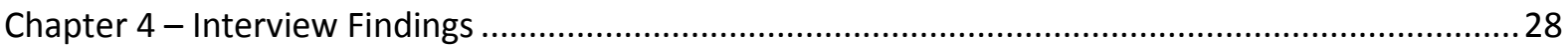


Page 3 of 97

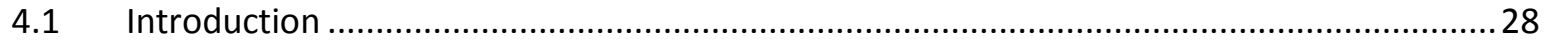

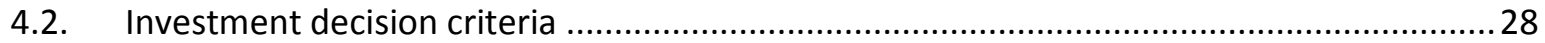

4.3 Programmes that can help start-ups become investment ready .......................................30

4.4 Some extra personal advice from angel investors in New Zealand that can help start-ups

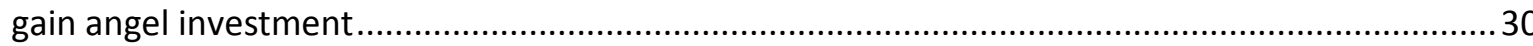

4.5 Angel investors' view on the New Zealand angel investment industry in 2014 ...................31

4.6 Angel investor advice on how to find an angel investor .................................................. 34

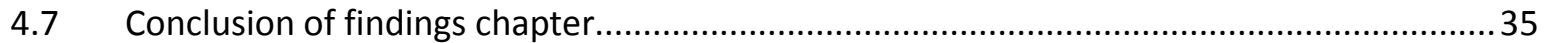

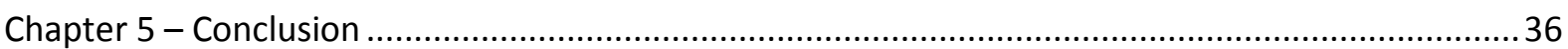

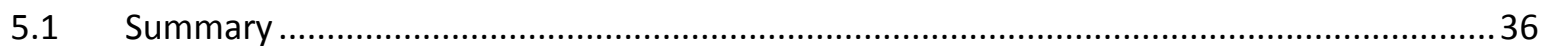

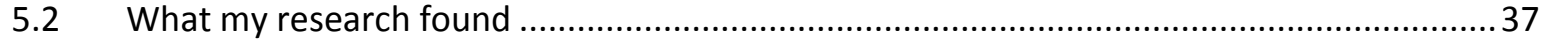

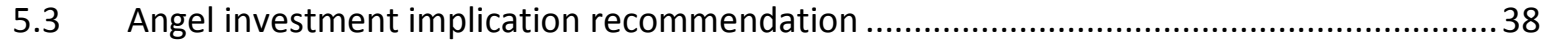

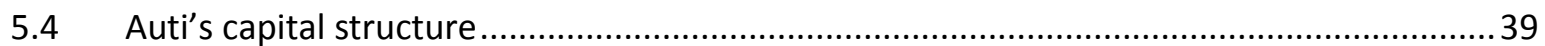

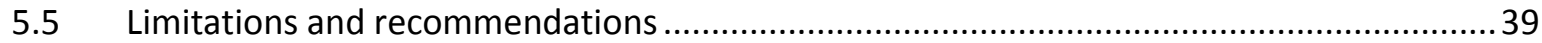

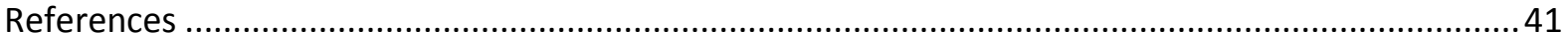

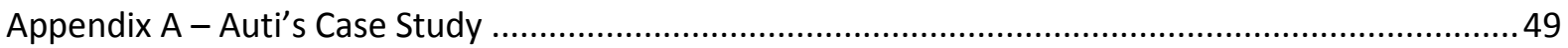

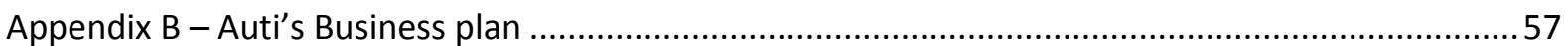

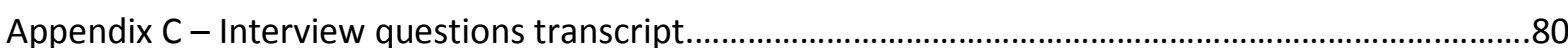

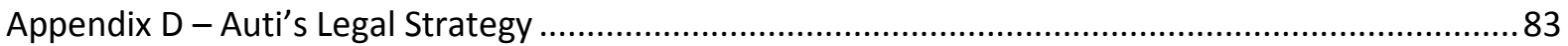




\section{Chapter 1 - Introduction}

\subsection{Masters background}

As part of the "Masters in Advanced Technology Programme" each student had to select a high-tech start-up that they wanted to be involved in throughout the year. Each individual would bring value to the start up through their background and experience. The start-up I selected was an interactive robotic toy called "Auti". Project champion, Helen's envisioned goal was for the toy to help children with autism learn positive behaviours.

Our team consisted of two main individuals not including the product champion (Please refer to Appendix A to learn more about the team, team dynamics etc.). My individual responsibility in terms of contribution to the team was to establish a strategic business plan, including a growth strategy for the project. Gaining funding is a critical part of any start-up's growth (Ministry of Economic Development, 2007). Financial planning forces companies to think about their goals. A common goal most companies have is the goal to grow (Ross et al., 2002).

Due to its high influence, funding can be the difference between a start-up company's failure or success, I decided to put the majority of my focus on funding for "Auti", this was done to reduce the chances that funding could become a Acknowledgments:

I would like to express my deepest appreciation to a number of people who have hugely contributed to the successful completion of both my individual thesis and the work which my start up team and I did towards creating value to our start-up 'Auti'.

My supervisor, Professor David Crick from the School of Marketing and International Business. David's enthusiasm into research, the way he passionately discussed research topics made my research much more interesting, he opened my mind to look into things I would otherwise have missed. Most importantly his constant support and advice not only shaped the core of my thesis but also shaped me into a true academic.

Programme director Doctor Paul Smith. His positive energy and optimistic view on things are characteristics which are critical to running a course such as 'Masters in Advanced Technology enterprise' which looks at creating new high tech products. The combination of having to create a 
Page 5 of 97

new technology and commercialising a product guaranteed stressful days and tears ahead. No matter what difficulties my team or I faced Paul always helped find a solution.

Kate McGrath, from the School of 'Chemical and Physical Sciences. Kate is the main person behind the creation of the Masters programme. Thank you for creating a platform where young entrepreneurs can open their minds and are given the opportunity to create. Innovation is the future, I hope one day to make an innovative stamp to this world, making a positive change. This programme has given me the skills, knowledge and confidence which undoubtedly helped towards achieving this goal.

Helen Andreae the project champion of 'Auti'. It was a great experience working with you.

Michael Elwood Smith who offered his time to be a mentor to all teams in the master's programme was a huge contributor to the success of all teams. Thank you Michael.

Last but not least thank you to everyone who makes 'Victoria University of Wellington' the amazing University that it is. I have truly enjoyed my time at 'Victoria'. It has been a privilege meeting everyone, including academic staff and students. My time at 'Victoria' has been a once in a life time experience which I will treasure forever. Reason for "Auti" failing as a business.

\subsection{Objectives}

The objective of this study was to identify the best suited funding sources, which I could then recommend "Auti" implement in order to help the company become a feasible, sustainable business. In order to make the most appropriate recommendations, I had to become financially literate. A study done in Canada found that weak financial literacy may be one of the biggest reasons start-up businesses do not succeed (Intuit, 2013).

\subsection{Research questions}

My thesis looks to answer three specific questions. Questions one and two are specific to my individual research conducted into the angel investment industry in New Zealand.

1) How do angel investors in New Zealand view the angel investment industry in New Zealand?

2) What do angel investors expect high-tech start-ups to have in place before they would consider investing? 
Thesis question three is related to the main theory of the thesis.

3) How relevant is the "pecking order capital structure" theory to high-tech start-up companies in New Zealand?

\subsection{Contribution}

This thesis contributes to practice as well as theory. My interviews with angel investors are "practice led", meaning that the research led to a new understanding about practice (Edmonds et al., 2006). In terms of my own research, a new understanding was formed on angel investment in New Zealand in 2014. Specifically, a common list of things angels throughout New Zealand look for in "high-tech" start-ups, before they would consider investing, was identified.

The main theory within this thesis is to do with the "pecking order capital structure", in relation to high-tech start-ups, therefore contributing to research done around the pecking order theory.

\subsection{Thesis layout}

This thesis is a reflection of the two facets of research that I conducted. The two approaches used were action-based research and in-depth Interviews. Action-based research aims to contribute both to the practical concerns of people in an immediate problematic situation and to further the goals of social science at the same time (Gilmore et al., 1986). Action-based research, as mentioned in this thesis, looks into the process that was taken to find the best suited funding sources for our start-up, "Auti". An in-depth interview was conducted with angel investors in New Zealand to get a better understanding of angel investment in New Zealand. Specific focus is put on "angel investment" in New Zealand as this is the preferred choice of start-up capital for "Auti".

The thesis begins with a literature evaluation. The first section will evaluate funding source literature that influenced us to select angel investment funding as something we wanted to get a better understanding of. Further angel investment literature will be evaluated, including the gap in literature that my individual research into angel investment fills. Research question three looks to see if our start-up, "Auti"'s capital structure follows the "pecking order capital structure", therefore there will also be a section within the literature review chapter that will include my main findings on past research, which has been conducted around the world, looking into if high-tech start-ups, such as "Auti", follow the "pecking order capital structure". 
Page 7 of 97

The definition of high-tech firms, also known as new technology based firms, is not clear, its application differs significantly depending on time, space, and authors (Laranja \&Fontes, 1998; Fontes \& Coombs, 2001). One way it has been defined by Little (1977) is "independent owned business established for not more than twenty-five years and based on the exploitation of an invention or technological innovation implying substantial technological risks".

Following the literature review chapter, my research methodology is described, specifically with regards to my individual research into angel investment in New Zealand, explaining what I did, why, and problems that I faced. The thesis then follows with main findings from my individual qualitative research into the angel investment industry in New Zealand.

The thesis conclusion will have six main sections. Sections will cover whether or not my research supports the literature, what my research contributions are, and an implementation section (recommending start-up funding implications for "Auti"). As my individual research looked into the angel investment industry in New Zealand, a majority of the implementation will be specific to what the "Auti" team should do in respect to approaching angel investment in order to have a higher chance of gaining investment. My recommended start-up funding implications will then be compared to the pecking order capital structure to show that it follows that structure. A section will also look into the limitations that my research faced. The last section will be recommendations in terms of further research needed to be conducted in order to support my research conclusions. 


\section{Chapter 2 - Literature Review}

\subsection{Introduction}

This chapter begins with an explanation of the pecking order theory and why I had decided to use this theory. This chapter also evaluates my main findings from my literature review into funding sources. These findings indicated that angel investment is the financing source our team should follow. The chapter concludes with main findings from my research into angel investment, helping me understand the angel industry more. Limited findings led me to conduct my own interviews with angel investors, as I was unable to find in-depth information on angels, due to the secretive characteristic of angel investors.

\subsection{Pecking order theory}

The pecking order theory suggests that companies prioritise their funding sources. There are three main sources when it comes to funding, they are internal funds, formal debt, and formal equity. Internal funds are also commonly known as non-formal debt and equity (AANZ, 2014) Internal funds include founders investing their own money into their start-up or gaining funding through friends or family. Formal "debt financing" can be defined as money being borrowed on credit that you look to repay in the future, in full including interest. Formal equity financing is money obtained from an investor, which could either be angel investors or venture capitalist firms (Hann \& Hinloopen, 1999). Money invested by an investor is exchanged for a share percentage in the company. Pecking order theory is based on the principle that corporations firstly prefer internal financing; secondly, debt financing; and least prefer new equity financing. As the pecking order theory suggests these preferences are based on the fact that the cost of financing increases with asymmetric information, which means that one party has more information than the other. Therefore when it comes to companies looking for funding, new equity brings higher costs as many companies hold certain information internally that they do not share with outside parties. Withholding such information creates greater uncertainty for outside investors, which means higher risk for their investments. In return for the high risk, investors ask for higher stakes in a company. Also because of this informational asymmetry, outside share purchasers will tend to under-price firms' shares (Myers \& Majluf, 1984).

There are a number of extra funding sources used by start-ups, which are listed below. A further informal type of financing, commonly used by start-ups, is bootstrapping, which can be defined as 
the use of creative strategies to gain control over resources (Harrison et al., 2004) or strategies that obtain resources without external financing (Freear et al., 1995). Bootstrapping financing can include sharing resources, taking out personal loans, which are then inserted into the start-up or going without some common essentials to help pay for start-up costs (Winborg \& Landstrom, 2001). Another category of financing is called "quasi equity", which fills the gap between equity and debt financing, it has the characteristics of both debt and equity. Quasi equity is also commonly referred to as revenue participation investment. It is usually structured as investments where the financial return is calculated as a percentage of the investee's future revenue (Cheng, 2008).

Grants are another type of funding source commonly used, grants are often described as "free money". There is no interest on grants and the provider of the funding does not take an equity stake or any claim over the company. Sources, such as central, regional, or local government, provide companies with grants. One of the biggest disadvantages of a grant is that it takes a lot of time and effort to complete a grant application (GRANT finder Ltd). As we are a New Zealand-based start-up, the grants we are more likely to obtain for our start-up, "Auti", are within New Zealand. In this day and age the term "grants" is becoming dead in New Zealand, grants are now seen more as investments. For example, the Ministry for Business, Innovation and Employment, which is responsible for investing in many early-stage high-tech companies in New Zealand (MBIR, 2014), wants to work with start-ups and partner with companies, rather than just giving out grants and not having any involvement with start-ups. Due to this, I would categorise grants as a type of formal equity. Although equity is not taken from a company, the investment aspect of this type of funding source fits well with equity financing (FRST grants, 2008).

At the end of this thesis, I will recommend funding implications for "Auti", each funding source that will be recommended will be categorised in one of these categories, in order to evaluate whether the pecking order theory of financing describes the capital structure of high-tech start-ups, such as "Auti", in New Zealand.

The pecking order theory is one of the most common and influential theories that describes corporate firms' financing (Frank \& Goyal, 2003). Research, which looked into 157 firms in the United States, found the pecking order theory to be a great describer of corporate financing, it seemed to definitely be the case for mature firms (Shyam-Sunder \& Myers, 1999). As information asymmetries influence firms' capital structures and due to the fact that high-tech firms are prone to 
information asymmetries, the "pecking order theory" seems to be a good theory to describe hightech firms' financing.

\subsubsection{Pecking order theory and high-tech firms}

There is a limited number of studies that have been done around high-tech firms and their financial strategies. The past research that has been conducted shows a variety of different results in terms of the pecking order financial strategy and how it relates to high-tech start-ups. Below are a number of studies that have been conducted around the world on this topic and their findings.

A number of studies have concluded that personal funds were the initial source of funding for a majority of high-tech start-ups. Studies include a study done on Belgian firms (Manigart \& Struyf, 1997), a study conducted on high-tech companies in Britain (Moore, 1994), two studies conducted in Italy - one in the year 2000 (Guidici \& Paleari, 2000), the other in the year 2007 (Columbo \& Grilli, 2007) - as well as a 1997 study conducted in Denmark (Empirical Study in Denmark, 1997). Each of these studies also concluded that most of the high-tech companies seemed to follow the pecking order theory. Each study also came to their own conclusion in relation to high-tech start-ups' capital structures.

The Belgian study made two key findings in their study. Firstly, it found that as firms matured and became less informationally opaque, they were able to attract external funding, such as angel investors. Secondly, the longer a start-up firm was able to survive on its own with personal funds, the lower the cost of external capital and the more control retained by the entrepreneur (Manigart \& Struyf, 1997). The year 2000 Italian study found that high-tech companies least preferred gaining funds from external sources as they did not want to lose control. In the cases when external funding was used, it was used for managerial expertise. They also concluded that different technology industries rely on different sources of capital. The more high-tech a company was, the more it relied on external capital due to the difficulties of assessing risk associated with new technologies. The majority of less technological start-ups appeared to follow the pecking order theory, although more high-tech companies, for example those in the biotechnology industry, used more external capital, such as angel or venture capital (Guidici \& Paleari, 2000).

Although the study conducted in Denmark found that a majority of the start-ups in their study followed the pecking order theory, they also concluded that those firms tended to be less technological start-ups. The researcher concluded that high-tech start-ups' capital structure 
Page 11 of 97

depended on the type of technology used (Empirical Study in Denmark, 1997). The 2007 study in Italy identified that firms that used debt financing over equity raised less in total than those that used equity (Columbo \& Grilli, 2007).

\subsection{Start-up funding literature}

This section outlines the main findings into the capital structure of start-up firms, which helped me become financially literate and influenced my funding implementation recommendations for "Auti". Capital structure refers to the mix of debt and equity used by firms to finance their long-term fixed assets (OECD, 2000). Specific focus is put on high-tech firms' capital structure because our start-up product "Auti" is high-tech.

The first capital source used by entrepreneurs to fund their start-up is typically through either inserting their own personal money or gaining money from friends or family (OCED, 2011). There are a number of reasons for this being the case. Most common reasons include difficulties in accessing other means of funding and founders wanting to keep control within the internal team (Bhide, 1992). Founders also use their own funds to signal their commitment in their start-up to potential investors, thus the use of internal funds can be a stepping stone to external funding (Myers \& Majluf, 1984).

Family and friends are less worried about investor protection due to their connection to the entrepreneur, which reduces the risk of the investment (Nofsinger \& Wang, 2009) therefore making the investment process less complicated. An example of this is that friends and family tend to not use a term sheet when making an investment. Term sheets are usually only used with formal angel investment. A term sheet is a document that an investor prepares for presentation to the company in which the investor states the investment that he is willing to make in the company. It portrays the agreed valuation and sets out the following things, amount of investment, ownership claims and rights, and responsibilities of each party. It is usually a long process that involves lawyers, which is a cost to a start-up (Smith \& Smith, 2003).

Various researchers state that angel investment is the most important source of funding for startups because angel investors bring useful resources to start-ups (Morissette, 2007; Freear et al., 2002). Angel funding falls in between informal funding, such as founder's funds, friends and family, and venture capital (Sohl, 1999). Angel investors are known to invest in start-up companies, they are also known to accept higher risk, therefore it has been proven to be a main source of funding for 
Page 12 of 97

many start-ups (New Zealand Venture Investment Fund, 2007). Angels are seen as key resources to start-up firms as they commonly provide strategic and operational expertise (OCED, 2011). Angel financing typically comes before venture capital financing, the amount of funds inserted are much smaller (Wong, 2002). Angel investors also often act as mentors to young firms, which helps prepare them for later stage funding (Mackie, 2004).

Angels fund approximately 100 times as many seed-stage high-tech firms as do venture capitalists (Preston, 2007). Venture capital is often a follow up to angel investment. Venture capital can be defined as investments made to new firms with private equity made by institutions, firms, and wealthy individuals (Anders, 2006). Venture capital funds are managed by professional investment managers (Fenn et al., 1995).

Angels and venture capitalists rely on each other. Angels often need venture capitalists for follow-on investment and venture capitalists enjoy deals that flow from angels, as those start-ups have been helped to grow (New Zealand Venture Investment Fund, 2007). Venture capital is a subset of a larger private equity asset class, such as expansion or growth capital (OECD, 2011). Venture capitalists are also known to invest in start-up stages but usually ask for a large portion of the company and control (Ministry of Economic Development, 2007). Fewer venture capitalists are investing at the start-up stage than before (OCED, 2010). Studies also show that trends in venture capital investments seem to be unfavourable for new high-tech firms (Spann \& Adams), angel investors are funding firms all the way through exit rather than relying on venture capitalists to take over (Peters, 2010).

\subsubsection{Difficulties with gaining start-up funding}

Gaining funding is seen problematic for most start-up firms (Bruno \& Tyebjee, 1985). Due to most entrepreneurs wanting to maintain control, the biggest problem is not accessing funding but reducing reliance on external finance (Bhide, 1992). Past research has found a number of factors influence start-up firms' difficulties in accessing financing, which affects their capital structure (Atherton, 2009).

Information asymmetry-based explanations of firm financing are particularly relevant to start-ups, due to a lack of trading history and the practical barriers to undertaking due diligence on new, unproven ventures (Cassar, 2004). Start-ups also find it hard to raise funds because of their limited knowledge of the investment process, therefore they may not be aware of the funding options available to them and may not know how to develop an attractive investment proposal (Ministry of 
Page 13 of 97

Economic Development, 2007). A lack of exit opportunities for investors is a significant problem that constrains sources of seed, start-up, and growth capital (OECD, 2011). External investors also hesitate in investing due to the moral hazard issue, which means that entrepreneurs have the incentive to misuse those firms for their own benefits (Denis, 2004).

\subsubsection{Funding literature for high-tech start-ups}

Research has found that access to finance is not a barrier to growth for a majority of New Zealand firms with a marketable proposition. However, for high-tech start-ups gaining funding is significantly problematic (Ministry of Economic Development, 2007). Most high-tech firms are built upon intellectual capital rather than on physical assets therefore making it difficult to evaluate their value. High-tech firms also have a difficult time gaining debt financing, such as bank loans, due to a lack of tangible assets that banks can use as collateral (Colombo \& Grilli, 2007). High-tech firms also face a higher risk of failing due to the threat of new technologies, therefore banks are more reluctant to lend money to them (Guidici \& Paleari, 2000). It seems to be extra difficult for many high-tech startups as money needs to be raised for a number of years to pay for development, as most often with new technologies a number of prototype versions must be created before a product can enter a market (Spann \& Adams).Therefore most high-growth companies tend to seek external financing as internal finance does not provide enough to finance high growth (Michaelas et al., 1999). Debt financing is the most common source of financing for start-up firms, including innovative firms, although innovative and high-growth firms look for equity funding more than other types of start-up firms (OECD, 2010).

Due to the fact that a large amount of money needs to be raised and gaining external funding from sources such as banks is unlikely for high-tech start-ups, founders often find unique ways to raise money for their start-up. A study done in United States identified one such unique way high-techs gain funding is through a bridge business. A bridge business is specifically created to raise money for the development of high-tech products. Advantages of a bridge business include founder's ability to retain control of their start up, help funding the development of their technology, creating a track record for the business by creating relationships with banks, and building business experience, which many high-tech founders lack. As well as finding unique ways to fund a start-up, founders tend to look for funding from external equity. Angels tend to invest in early stage funding to high-tech startups if amounts are less than $\$ 500,000$ (Spann \& Adams). 
Page 14 of 97

Thanks to the Internet many new funding options are available to start-ups, which were not available before the Internet. The main funding source that has been established is "crowd funding". Crowd funding can be defined as raising money directly from a large number of people all putting in significant small amounts of funds (Buysere et al., 2012). There are number of online platforms that make crowd funding possible. A popular New Zealand crowd funding website is "Pledgeme". Another two funding options that have recently been developed in a number of countries is "equity crowd funding" and "peer-to-peer lending" also known as "debt crowd funding". Both these funding sources are branches of crowd funding and have the potential to significantly influence start-ups' capital structure. Before these funding sources were available, start-ups found it extremely difficult to gain debt funding from banks, due to their lack of collateral and sufficient cash flows and the presence of significant information asymmetry. Also there were a limited number of people and organisations that start-ups could approach when looking for equity funds, for example angel and venture capital investors. Peer-to-peer crowd funding allows ordinary people to lend money to companies, giving start-ups a greater chance of finding someone that will want to lend them money (Snowball Effect, 2014). Equity crowd funding is a means by which small companies can raise capital from investors other than just those who meet the "accredited investor" standard (Townsend, 2014). Currently only a few countries have passed laws to allow peer-to-peer lending, such as the United States and United Kingdom (Galloway, 2009; Goff, 2012). Many other countries, including New Zealand, are currently waiting to have peer-to-peer lending legalised. New Zealand expects peer-to-peer leading to be legal by July 2014 (Vaughan, 2014). Equity crowd funding has recently become legalised in New Zealand. Equity crowd funding platform companies must first apply for an equity crowd funding licence through a licensing process, which was opened on 1 April 2014 (Bacova, 2014).

Research has found that recently many start-ups are using crowd funding to seek financial help for their start-up (Kleemann et al., 2008; Lambert \& Schwienbacher, 2010). As equity and debt crowd funding are recently established funding sources, there is limited literature surrounding how these funding sources influence the capital structure of start-up companies.

The main points stated above led me to select angel investment as one of the main start-up funding sources our team should approach for "Auti" at the current stage. Most of our assets are intangible therefore bank loans are not a feasible option for us and we have already used up a large amount of personal funds to fund the prototypes of "Auti". The benefits of angel investment, such as angels 
Page 15 of 97

bringing in useful resources to a start-up, are something that interests us. This was our first business, none of the core team had prior experience of running and building a company. I therefore focused on angel investment literature to help gain a better understanding of angel investment, which would help our team gain angel funding for "Auti".

\subsection{Angel investment in general literature}

The angel investment sector is growing, becoming more formalised and organised (Ibrahim, 2008). Angel investors used to be quiet about their investments and searched for deals in secret. Due to the expanding growth of the angel industry, angels are becoming less secretive although they are still somewhat private about their activities. Due to this, more angel funding is available and more startups are aware of angel investment and its benefits to start-ups (McKaskill, 2009).

Angel investors are individuals that have available funds and are ready to invest in entrepreneurs' ideas (Fiti et al., 2007). They are professional investors who specialise in investing in profitable startups (Nofsinger \& Wang 2009). They fund private businesses that are not owned by friends or family (Scott, 2009). There are various types of angels, although angels tend to be males between the ages of 45 and 60 (Ministry of Economic Development, 2007). Although angels come in many shapes and sizes, anecdotal and conceptual evidence suggests that they collectively perform an increasingly vital role in start-up financing (Sohl, 2011).

Angels usually help out a business in more ways than just providing funding. Angels have industry experience, experience in building a business, access to venture capital firms, and access to strategic partners (McKaskill, 2009). Angels can either be formal or informal investors. A formal angel investor is one that operates under a visible angel network (NZTE, 2009). Formal angel networks are organisations whose purpose is to bring together new small- and medium-sized firms and angel investors (European Business Angel Network Code of Conduct, 2014).

Informal angel investors are ones that do not function through a visible network. They are investors who can be found through informal networks, which include personal networks. One example of a good way to find an informal angel is by approaching sources such as your accountant or lawyer and by contacting a local Chamber of Commerce, which will often be able to point you to the direction of an angel (NZTE, 2009). 
Page 16 of 97

Studies have found that there are a number of reasons why angel investors invest. Money is not the single motivation for angel investors (Macht, 2007; Baty \& Sommer, 2002). One main reason angels invest is for the chance to add value to a business (France Angels, 2004). Angel investing is about passion. Angels get involved because they enjoy helping start-up firms. Through means such as mentoring, the investor is partaking in the development of an up-and-coming business (McKaskill, 2009).

\subsubsection{Angel investment in New Zealand}

Angel investment is an important source of capital for innovative start-ups with high growth potential that are developing unproven products or technology. The following is past research undertaken specifically into the angel investor industry in New Zealand.

The angel market in New Zealand for a long time had been very secretive, in the last few years awareness of the market has grown significantly (Ministry of Economic Development, 2007), which is a reason for deals, as well as the industry, becoming better as a whole. Greater awareness means that more deals are put through and more individuals are joining formal angel groups in New Zealand (NZ Venture Investment Fund, 2007). In 2006, the government created a "seed investment fund" the main purpose of this initiative was to develop the angel investment market (Ministry of Economic Development, 2007).

Investments tend to be made through informal rather than formal networks. Approximately twice the number of deals are made through informal groups. Angels tend to invest in their own region and in their own area of expertise. There are angels who will consider a range of investment opportunities and others who invest in a specific region. Angels in formal networks tend not to differentiate between seed and start-ups. Currently, there is a significant lack of lead investors (NZTE, 2014). A lead investor usually organises a round of financing and contributes the largest amount of the capital to a deal (Lead Investor, 2014).

The current chair of the Angel Association in New Zealand is Marcel van den Assume from Wellington. The purpose of the Angel Association is to "bring together the business angel networks and early stage funds to work towards an agreed national vision" (AANZ, 2014). Below are some key 2013 statistics of the angel investment activity. Total capital invested was $\$ 53,230,971$ with a total of 116 deals. Fourteen companies receiving a first round of angel investment in the last six months of 
Page 17 of 97

2013. Of the $\$ 53.2 \mathrm{~m}$ invested in $2013,20 \%$ ( $\$ 10.5 \mathrm{~m})$ was new investments. The average deal size grew significantly from $\$ 298,968$ in 2012 to $\$ 497,486$.

Auckland was the highest capital investment region in the country with $55 \%$ of dollars being invested there. The software and service sector made up $42 \%$ of the deals, followed by technology hardware and equipment at $13 \%$. In terms of percentage of dollars of capital invested by region, software and services led with 32\%; pharmaceuticals, biotechnology, and life sciences followed with 19\%; and technology hardware and equipment at 12\%. In December 2012, the Angel Association of New Zealand estimated there were about 350 angels active in seven networks throughout New Zealand. By December 2013, it was estimated that over 150 new investors engaged in angel investment (NZVCF, 2014).

Angels had identified in a 2007 study that New Zealand founders have to increase their understanding of the importance of capital in their growth. Angels also mentioned entrepreneurs needed to have a better understanding of the investment process (Ministry of Economic Development, 2007). A programme, which is no longer available, helped New Zealand start-ups become investment ready, this programme was called the escalator programme, which was run by New Zealand Trade and Enterprise. It helped in a number of ways, such as helping firms develop a business plan. New Zealand Trade and Enterprise is the government's international business development agency (NZTE, 2014).

There are a number of key things angels tend to put a great importance on. Many angels find a relationship between founder and investor important, "no matter how comprehensive the due diligence process, individual shortcomings may not present themselves for years, so the relationship with the founder is vital" (NZTE, 2014). Studies have shown that out of every 10 businesses invested in, only one will be a "home-run" returning five-ten times. Therefore angels usually look to invest in firms they believe will have an internal rate of return of at least $25-30 \%$ per year. The majority of angels invest in a firm that is offering a product that will solve a major problem in the market. Such products usually have some sort of intellectual property, or IP, attached. Angels need to know whether a product is unique, has it been validated, has it or can it be patented, and whether or not there is freedom to operate; meaning does your firm have the ability to develop, make, and market products without legal liabilities to third parties (Lewis, 2008). As patents can be very expensive and are sometimes not the only or best option for a technology company, angels want to know what alternative tactics you have to protect your intellectual property. One example of a potential 
Page 18 of 97

alternative is being the first to market, which means being the first company to gain consumer confidence and gain the largest market share (First to Market, 2014). Angels also like to see that founders have "skin in the game". For example, founders have put their own money in the company (NZTE, 2014).

Rod Drury, a successful entrepreneur, mentioned that the New Zealand angel investment industry is small, which means most of the experienced investors get to see the bulk of the deals. Therefore founders have to make their first pitch "short, sharp, and compelling". And the pitch needs to be high quality on paper. Rod also mentioned that he looks for individuals who are smart, can project manage ideas, and turn them into a business (NZTE, 2014).

Formal networks usually specialise in something specific, for example a certain industry (Icehouse, 2013), therefore you cannot presume that each angel group operates identically. Saying this, there are common themes in how angel groups operate. For example, a number of formal networks have stated that, when choosing deals, they first look into the individuals behind the product, then look into the market and finally the idea/product. Andrew Duff, the co-founder of Icebox Angels in New Zealand, mentioned in an interview that this was the philosophy that Ice Angels followed (NZTE, 2014). Another angel group, which follows the same philosophy, is Angel HQ (NZTE, 2009).

\subsection{Conclusion}

The literature on angel investment increased my knowledge on angel investors, as well as the angel industry in general. As the research had stated angels tend to be secretive about their investments (which is why not a lot of personal, in-depth information about angels can be found), I had decided to conduct research using interviews into the angel investment industry specifically focusing on New Zealand, being that our start-up is New Zealand based. To date, there has been a lack of up-to-date research conducted on angel investment in New Zealand therefore my interview research also looks at filling this gap. 


\section{Chapter 3 - Methodology}

\subsection{Introduction}

My research into funding sources has two facets. The process of my research into funding sources as a whole and how this influenced my recommendation for our start-up were action based. I also conducted interviews with angel investors, which gave me more in-depth knowledge into the angel investment industry in New Zealand.

\subsection{Action-based research}

The process I took into researching funding sources was action based. Action research is also known as participatory action research (Lingard, 2008). It is intended to have both research and action outcomes (Dick, 1992). Most researchers appear to refer to action research as cyclic. They mention that the action research cycle consists of planning before action and review after (Dick, 1992). Action research aims to contribute both to the practical concerns of people in a current problematic situation and to further the goals of social science simultaneously (Gilmore et al., 1986). A number of factors separate action research from other types of research, such as it having a social dimension, the research is conducted in the real-world and aims to solve real problems (O'Brien, 2001). My research into funding had been specifically conducted in order to help find appropriate start-up funding for "Auti", which is a real-life start-up. Action research is an appropriate research method when circumstances require flexibility and when people are involved in the research (O'Brien, 2001).

This thesis is an explanation of the process my team and I went through in terms of researching, finding, and implementing funding for our start-up, "Auti". To be specific, the following actions were done on my part as I was in charge of looking into funding sources. Each week I would conduct my own independent research into funding sources and at the end of each week I would share my findings with the team. As the capital structure is a significant part of any firm's growth it therefore influenced my overall business strategy (please refer to Appendix B to view "Auti"'s business plan).

The action research cycle can also be seen as a learning cycle (Kolb, 1984). Action research affirms that experience can be a basis of knowing and that experiential learning can lead to a legitimate form of knowledge and influences practice (Tandon, 1996). In terms of this thesis, the process we took for researching funding sources, in order to find the most suitable start-up financing for "Auti", was our learning curve as it persuaded us to make certain decisions regarding funding for "Auti". 
Page 20 of 97

Action is through reflective cycle, participants collect and analyse data, then determine what action should follow. The chosen action is then further researched and an iterative reflective cycle perpetuates data collection, reflection, and action as in a corkscrew action (Wadsworth, 1998).

My collection of research data into funding lead our team to take the action of selecting angel investment as our first preferred choice of funding, therefore requiring me to undertake further investigation into angel investment. One of the main purposes of action research is to learn through action, which builds personal and professional development (Carr \& Kemmis, 1986). As mentioned in the introduction, after careful research identifying funding options available to us, as a team we decided that angel investment would the best suited funding source for "Auti" at the start-up stage. My individual research therefore focuses on the angel investment industry specifically focusing on angel investment in the New Zealand context. Existing literature surrounding angel investment in New Zealand is outdated therefore my research updates information on the angel investor industry in New Zealand.

\subsection{Process (interviews)}

In order to gain insightful information into the angel investment industry in New Zealand, I had to conduct qualitative research. Qualitative research involves methods such as participant observation, interviews, or case studies that help describe a setting or practice (Parkinson et al., 2011).

Open-ended interviews with angel investors were the most appropriate research method to gain information that was needed to answer research questions one and two. Open-ended questions are unstructured questions with no suggested possible answers (Foddy, 1993). A limited amount of insightful information is available on angel investors that would allow us to create closed questions that could be broad enough to get an insightful idea into angel investors within New Zealand, as each angel investor is different and operates differently. Information is limited as New Zealand angel investors tend to be secretive with regards to their investments (Ministry of Economic Development, 2007). Closed questions are provided with a set of answers a respondent can select from (Foddy, 1993).

Five of the eight interviews conducted were undertaken face to face, the rest where conducted via Skype, an online tool that allows peers or groups to conduct video-call conferences from anywhere in the world. Skype interviews were conducted in the cases were face-to-face interviews were not applicable due to outside influences, such as distance and angel investors' preferences. The video 
feature of Skype gives similar advantages to conducting interviews as face-to-face interviews. A negative of interviewing over the Internet, which is necessary for me to mention, is the problem of authenticity of identity (Fox, 2006). For those angel investors who I interviewed over Skype, I ensured that their Skype id and email were authentic and that I was actually speaking to the investor which I intended to interview. I did so by checking Skype identifications on the angel investors' LinkedIn profiles. LinkedIn is the largest professional online platform (LinkedIn, 2014). In some cases, I also emailed other angel investors which I knew may know a certain angel investor and asked them for that angel investor's Skype id.

Interviews were set to take no longer than an hour. It has been proven that respondents to questionnaires and surveys with large numbers of questions tend to answer "no" more often to speed up the interviews (Lehnen \& Reiss, 1978). Therefore the interviews were no longer than an hour to help avoid such answers. (Please refer to Appendix $C$ to view the full interview transcript.)

Face-to-face interviews have a number of advantages compared to other means of gathering information, such as conducting surveys or interviews over the telephone, which have the tendency to cause respondents to rush their answers therefore answers tend to be less rich (Dillman et al., 1996). Face-to-face interviews are preferred when the subject matter is very sensitive (Taylor \& Bogdan, 1984). Angel investment has to do with money, which is seen by many as a very sensitive topic.

Face-to-face interviews' advantages include:

- An interview environment engages respondents actively, which is known to make respondents more comfortable therefore more willing to give more in-depth answers (Boyce \& Neale, 2006).

- Interviews give the opportunity for an interviewer to observe a respondent's nonverbal communication, such as body language (Kvale, 1996). As mentioned above, angel investors tend to be quite secretive therefore body language could help pick up insight into the angel industry in New Zealand that would otherwise not be talked about.

- Interviews allow the interviewee to clarify the meaning of a question if an interviewee interprets the question differently from what the question intended to find, therefore 
increasing the chances of gathering information that would help answer the research questions. It is commonly believed that how people interpret questions will influence how they will arrive at their answer (Feldman, 1992).

Questions were strategically decided to be open ended due to the following advantage:

- Open-ended questions would allow for probing, for example to help answer "why" an angel investor feels a certain way or does and certain things (Taylor \& Bogdan, 1984).

Due to the nature of interviewing, the scope for introducing error and bias is significantly large and can affect a number of stages in the interviewing process, such as asking questions, recording the answers, coding the answers, and interpreting the answers (Fox, 2006). Due to this, it is important that steps are taken to help minimise error and bias. A pilot study can help ensure that objectives are met in an interview. A pilot study is a test study done in preparation of the complete study (Lancaster et al., 2004). Pilot studies can be done on a number of respondents preferably those from a similar sampling frame. Pilot studies can help identify errors in the interview and interview process, which the researcher can then edit or fix before conducting real interviews for their research thus reducing scope for error and bias. I conducted three informal pilot studies with three angel investors in Wellington, which helped me structure my questions more appropriately in order to help answer my research objectives. Early interviews influenced the questions and content of the following interviews (Bogdan \& Biklin, 1998).

\subsection{Methods of recruitment}

Both formal and informal angel investors from within New Zealand were welcome to be participants in my research, due to the fact that there are a limited number of angel investors in New Zealand and angels tend to have busy schedules. Although angel investors have a reputation of willingness to meet up over a cup of coffee to pass on some of their knowledge, most angels are not likely to meet up more than once therefore it was necessary to have all the right questions in place before approaching angel investors to partake in my research.

Qualitative research's purpose is not to generalise to a population, but to develop an in-depth exploration of a central phenomenon, which is best achieved by using purposeful sampling strategies (Creswell, 2005). 
Page 23 of 97

The sampling process taken to find formal angels is called "snowball sampling". The snowball sampling process usually proceeds after a study begins, for example a researcher asks participants to recommend other people for the research. Snowball sampling is a convenient method for studying hard-to-reach populations (Biernacki \& Waldorf, 1981). As a lot of angel investor information is not freely available the snowball approach of asking formal angel network directors to help find individuals for my study was the most appropriate approach to find credible formal angel investors for my research. The same sampling approach was taken to find informal angels, interview question 23 (please refer to Appendix c to view the full interview transcript) gave me insight on how to find informal angels for my research. The number of people interviewed is not seen to be of great importance. What is most important is that each interviewee can add something to the researcher's understanding of the setting (Taylor \& Bogdan, 1984). In terms of the angel investment setting in New Zealand, this is important as each angel is different and operates differently (Ministry of Economic Development, 2007).

My method of recruiting formal angel investors involved me contacting formal angel investor networks directly. Contact details for these networks can be found online. In order to find informal angel investors to recruit for my research, my plan was to network. An example of one of my networking activities included attending a start-up capital workshop event held in Wellington, New Zealand called "Deep Dive into Start-Up Capital 2013", organised by Icehouse Angels.

Once appropriate informal angels and formal networks had been identified, I sent an email with an invitation to partake in my interview. In terms of informal angels, an email was sent directly to the angels themselves but with regards to formal angel groups, an email was sent to the director of each network. Informal angels received an email including details about the research itself, its purpose, and gave the receiver of the email the opportunity to either decline or accept the invitation. The email sent to formal angel investor networks was slightly different from the email sent directly to individual angels as it did not directly ask a specific angel to be part of my research. It asked the directors if they could help find members from their angel groups that would be interested in partaking in my research. Once I received response emails confirming willingness to participate in my research, I followed by sending a second email asking willing participants to select a date and time for the interview and preference for how they wanted the interview conducted. In terms of formal angel network directors, if they agreed to find participants for my research they would then send me contact details of suitable angel investor candidates, who I then emailed. 
The initial email was sent at the beginning of November 2013, three weeks in advance of the first interview. Follow-up emails were then sent to each angel investor who agreed to partake in my research a week before their scheduled interview with me.

\subsection{Predicted number of participants}

Currently there are 15 formal angel investment groups in New Zealand. Thirteen of those groups are partners with the seed co-investment fund in New Zealand (Ice House, 2013). Seed co-investment fund is an early stage, direct investment fund (Seed Co-Investment, 2014). For the purpose of my research, I planned to interview at least one angel investor from each formal network, this would provide a good indication of the formal angel investor market in New Zealand. Finding informal angel investors is a time consuming task thus, due to time constraints, I planned to interview at least one informal angel investor.

\subsection{Actual number of participants}

Although I had contacted each formal angel investment group in New Zealand, I was only able to get responses from seven of the networks. After my initial email to those seven networks, I was contacted back by each of the networks all with a similar response, thanking me for contacting them and they would try to find angels from their network to contribute to my research. Overall, I heard back from four of those seven angel networks with contact details of angel investors from their network who were willing to partake in my research. The names of the four network groups were Ice Angels, Flying Kiwis, Enterprise Angels, and Angel HQ. Overall eight angels partook in my research, one was an informal angel the rest were formal angels.

\subsection{Reliability and validity}

All qualitative research that looks to have any significance needs validity and reliability (Cavanagh, 1997; Patton, 2001). Reliability is defined as the extent to which a questionnaire, observation, or any measurement procedure produces the same results on repeated trials (Charles, 1995). Self-report surveys or interviews are a viable option for researchers who are looking to get an insight about people. This information is known to be useful (Northrup, 1997). Past research has also found that self-reports have a tendency to include patterned ambiguities due to people's memory gaps. Selfreports are known to be biased in interview circumstances, respondents often tend to stretch the truth (Henry et al., 1994). 
Due to these two factors, the reliability of respondents' answers and the reliability of willing interview candidates needed to be checked. Prior to conducting interviews, I undertook primary research on each willing participant for my research. Primary research refers to gathering data for the first time for a specific purpose (Grafton \& Jones, 2010). Primary research helped check reliability in two ways.

Having information about each individual at the time of the interview helped refresh respondents' memory therefore helping respondents answer certain questions in greater depth. For example, one of my interviewees mentioned they did not have any prior experience investing in high-tech startups. Mentioning to that interviewee that a few years back in an interview they had mentioned a high-tech start-up they had involvement in, helped refresh that interviewee's memory, which in turn helped answer questions to my interview. Primary research on willing candidates led me to investigate and find reliable candidates to interview. Finding reliable, formal angel investors was much simpler than finding reliable informal angel investors. Formal angels who contacted me were recommended by respected directors of formal angel groups.

There are various ways qualitative researchers prove their findings are reliable. One sufficient method is to see whether the findings obtained from their qualitative analysis can be replicated (Coolican, 1994). I did this by comparing my interview findings with available reports and statistics on angel investment in New Zealand. Reports were provided by the New Zealand young company finance, available online (NZ Venture Capital Association, 2014). These reports measure angel investor activities annually.

Validity determines whether the research measures its purpose and how truthful research results are (Joppe, 2000). One of the main ways to measure validity for qualitative research is through rich, thick description (Creswell, 1998) therefore providing credibility in terms of in-depth exploration of a central phenomenon. Although in my research I was not able to interview all angel investors in New Zealand, observing repetition in answers to key questions in my interview from angels, who are "information rich", helped me to understand the angel investor industry in New Zealand.

\subsection{Triangulation}

Triangulation refers to the use of multiple sources and methods for collecting data (Creswell, 1998). As the research into the angel industry in New Zealand is qualitative, triangulation is seen as one of the most effective ways to test, in order to improve, the reliability and validity of research or 
Page 26 of 97

evaluation of findings. Triangulation strengthens a possible diverse construction of reality (Patton, 2001). Constructivism values realities that people have in their minds. To establish valid and reliable diverse realities a number of methods of searching and gathering data are necessary (Johnson, 1997). An open-ended perspective in constructivism adheres to the notion of data triangulation by allowing participants in research to assist the researcher with the research and data collection. As mentioned, initial pilot interviews were conducted with angel investors that helped guide my interview questions and layout. Using multiple methods, such as observation and interviews, in my research led to a more valid, reliable, and diverse constructions of realities. Triangulation is also an important step in analysing qualitative data. Researchers use investigator triangulation and consider the ideas and explanations made by additional researchers studying the research participants (Johnson, 1997). In terms of this research, I shared answers collected from my research with my team members in order to get their perspectives on answers to questions.

\subsection{Data analysis}

The purpose of qualitative data analysis is to uncover emerging patterns, understandings, insights, themes and concepts (Patton, 2002). Qualitative data, such as interviews, is difficult to analyse. The description of people's lived experiences, events, or situations is often described as thick (Denzin, 1989). An important step in analysing qualitative data, which I used, is "coding". Coding is the process of translating speech into meaningful categories, which allows researchers to organise large amounts of text and discover patterns that would otherwise be hard to detect (Analysing Interview Data, 2011). As suggested by Bogan \& Biklin (1998), my process of coding included initial coding, I created categories of codes. When listening to my interviews, I matched answers into the appropriate categories. I ensured reliability when analysing my data, for instance I made sure that I did not miss out on any key findings by replaying, writing out each interview, and highlighting key points.

\subsection{Problems that I faced}

Throughout my recruiting process I faced two main problems. The first problem was not hearing back from chosen participants for long periods of time. The second problem faced was participants changing dates and times from the initial planned meetings. The main contributor to these problems was the timeframe the angel investors were contacted during, the end of 2013 , a holiday season. These problems delayed the end date of my research. 
Page 27 of 97

\subsection{Conclusion}

My independent research into the angel investment industry in New Zealand, using interviews, gave me in-depth knowledge, which in turn influenced my actions with regards to recommendations of approaching angel funding. The next chapter will discuss my main findings from my interviews with angel investors. 


\section{Chapter 4 - Interview Findings}

\subsection{Introduction}

In this chapter, I will state the main findings from my individual research into the angel investment industry in New Zealand. This chapter also answers research questions one and two. This is an indepth look into the angel investor industry in New Zealand in 2014, giving a more personal insight into the industry.

\subsection{Investment decision criteria}

Research question two: What do angel investors expect high-tech start-ups to have in place before they would consider investing?

Companies need to do a little bit of work to look at the feasibility of their idea by doing such things as stated below, the more work that is done before approaching an angel investor the better chance of gaining angel investment. (I have categorised these into categories of importance based on what angels indicated.)

\section{Checklist - very important:}

All angels interviewed indicated that the following things should be in place. Entrepreneurs should prove they have put a real effort into creating their start-up and are not just at the idea stage; have an initial start-up team assembled; and show a level of investment, this can be done by inserting personal money into the start-up or through unpaid time. Angels want to see skin in the game. Angels also stated start-ups must have undergone research with regards to intellectual property for the following reasons, to prove the company has freedom to operate and is not infringing someone else's intellectual property. Also for start-ups to understand their options and gain a grasp of what the relationship is with commercialising a product and protecting it. Here follow three quotes regarding intellectual property made by three different angel investors: "Do not assume that you need to patent your product." "Intellectual property is critical but what is more critical is finding the right answer for the type of product." One angel quoted that start-ups should question "does protecting IP help your path to gaining market share therefore making the company money?" Two angels mentioned that if intellectual property is the company's best option, start-ups need to decide what countries to get intellectual property protection in. "IP is expensive, look into the markets that 
Page 29 of 97

you think have the most potential for your product and look into registering it there." Two angels interviewed recommended that entrepreneurs spend money consulting a patent lawyer and believe it is a great investment.

All except one angel mentioned the importance of a business plan. The following were things they wanted start-ups to cover in the plan, such as key competitive advantage, market research, exit strategy, indication of how a product can be scalable, business model - showing the planned path to commercialising the idea, and market validation proving there are potential customers wanting to buy the product. One angel mentioned wanting to see a realistic development cost of getting the product from beta stage to production. A quote from one angel in regards to writing a business plan, "Be clear around what you are trying to achieve."

Three angels mentioned wanting to see at least a beta product developed. One of those angels also stated they would expect to see proof of the technology working, "Sometimes this means you will need to see that it stands up to stress testing." That angel also mentioned that as well as seeing proof of the technology working, they wanted start-ups to show that the product is reliable, for example enough people have used it and are happy with it.

Two angels indicated wanting start-ups to have all relevant documentation sorted, such as the financials and contracts, so that they could be ready for a due diligence process. Quote from an angel, "Remember you are selling a business to angels, not a product or service." One of those angels mentioned that financial documents are also necessary to show angels what funding sources you do have and how the money is being spent, showing your ability to manage money.

\section{Checklist - important but not vital:}

All angels indicated that although seeing external investment is a good signal of commitment it is not something they see as being vital, it is often hard for a start-up to gain external funding from sources other than friends and family. It was mentioned by five of the angels that start-ups should only have a few friends and family investments, ones who will bring added value to the start-up, not just provide the company with money. Angels mentioned that start-ups with an overload of friends and family funding can sometimes be seen as unattractive. One of these angels quoted, "Rather than getting heaps of friends and family investment, try to bootstrap it as much as possible, keeping it as tight as you can." 
Page 30 of 97

One angel stated that seeing investment from another angel investor can also show commitment, angels will have verification indicating the team is reliable therefore reducing the risk for angels.

One angel mentioned that although angels do not expect start-ups to have all necessary people in place, such as financial or marketing people, they do like to see an indication of research, including finding out costs of hiring such people and researching other potential members who would be good assets to the company. Another angel mentioned that they wanted to see external verification that a start-up's idea/product is unique.

\subsection{Programmes that can help start-ups become investment ready}

Angels who had a part in my study identified programmes they believed could benefit start-ups who are looking for funding.

Four angels recommended entrepreneurs look into escalators throughout the country for example Lighting Lab, which is located in Wellington. Escalators put start-up teams through a process, focusing on raising investment at the end. Four angels recommended incubators around the country, such as ecentre and Ice House in Auckland. Incubators help start-ups in various ways to prepare them to raise money. Three angels mentioned approaching angel groups as most of them run useful programmes. Economic development agencies that offer a variety of services and programs were brought up by two angels, one of those angels mentioned that Enterprise Angels, in collaboration with Priority One - which is an economic development agency - does a number of programmes that help companies become ready for investment. Two angels also mentioned the NZTE Better by Capital programme.

\subsection{Some extra personal advice from angel investors in New Zealand that can help start-ups gain angel investment}

One angel recommended that entrepreneurs connect as early as possible with an angel group and keep in touch. He said, "The point is if you keep a connection then later down the line, when you require money, it will be much easier to attain because you are not coming out of the blue."

Another angel recommended asking for advice, "If you want money, ask for advice first. Because advice is easy to give and if you are not quite ready to ask for money and you ask for money it is very difficult to reengage from that position." Asking for advice before doing something can help you save 
Page 31 of 97

money on unnecessary things, for example many entrepreneurs spend a large amount on developing a product before conducting market validation.

\subsection{Angel investors' view on the New Zealand angel investment industry in 2014}

\subsubsection{Research question 2: How do angel investors in New Zealand view the angel investment industry in general?}

Two angels stated a lot of the angel activity is unknown to outsiders because this activity happens quietly, not through formal angel groups. One of those angels stated, "If you go through the New Zealand companies register you will see there are huge numbers of people who are shareholders in small companies around NZ, this suggests to me there are many people working outside the formal angel investor networks."

Six angels stated that there were a small percentage of active angels. Active angels are seen as being absolutely vital. Angels had indicated the importance in expanding the number of active angels. The following reasons were mentioned indicating why angels were not active in deals: not having the time or believing other angels are more suited to take the role of active angel in a certain deal. Also many angels are relatively new to angel investment therefore are still in the learning process. One angel said, "Although there is a small percentage, there are always at least one or two angel investors who have an understanding or experience in a sector and who are willing to get more involved than just investing money into the business." The most common way angels defined "active angels" was as individuals who are involved with the business more than just inserting funds. One angel mentioned that Flying Kiwis, a newly established angel network group, has a collective fund where all angels put money towards the due diligence, evaluation process therefore giving angels incentive to be part of the due diligence process and want to be more active. That angel said, "Money that they are investing is sort of like the glue that is making them work together."

All except one angel stated that there are a small number of lead investors and that this is an ongoing problem for most formal angel groups. Most frequent terms used to define a lead angel were someone that leads the due diligence process, tends to invest the largest amount of money in a deal, and is willing to speak for that start-up to attract other investments. One angel stated that "being a lead investor is a time intensive role, our angel network is always looking at ways to bring more lead investors, by taking a role in due diligence and supporting them when they take on companies, this is done to the make the lead investor feel more comfortable in taking on that role 
Page 32 of 97

again and again". Another angel stated that "Lead investors can be a group, not just an individual. The party that is the first and significant investor is the lead investor, they set the terms. Inside the Ice Angel group, for example, you will have a lead investor who leads a group of angel investors who will electively do the due diligence and they will collectively negotiate the terms. So you have a leader in that deal who orchestrates the due diligence and the term negotiation. Once this is done, then actively that angel group becomes the lead investor. They have now negotiated separate terms for other investors to come in and syndicate."

Six angels mentioned that the New Zealand angel industry was very active, four angels said that it is still relatively new and two angels said that it had enormous potentially to grow, one angel said, "It has potential to do more for the NZ economy." All angels mentioned that the angel investor industry is growing generally nationally. One angel said, "This growth means active angel and lead investor numbers are also on the increase." Two angels stated growth is significantly influenced because angel investment awareness is growing.

Two angels mentioned that more angel networks have been formed over the last five years. Two angels discussed that different angel groups have different niches and they tend to attract that sort of start-up. One angel stated that Ice Angels is the biggest network in New Zealand and therefore is more open to different niches/sectors. An angel explained that one of the basic philosophies and principles of angel investing is that angels tend to look for exit strategies, which can include listing a company or selling a company. That angel said, "This might not sit well with someone who is really looking to grow the company for the long-term therefore such individuals would prefer gaining investment from a non-formal angel."

Six angels mentioned that investors are trying to spread their risk, one of those angels suggested that for that reason the average amount invested in a start-up deal in the first round is much smaller than before. Another angel said that a reason for angels spreading their risk "is due to the global financial crisis, angels are more careful with what they do". The average amount invested, as indicated by the angels in this research, was $\$ 10,000-\$ 20,000$. One angel said, "The main reason for this was due to the high risk of investing in high-tech start-up companies." Another angel said, "I would invest less than $\$ 10,000$, where it is clear that there is going to be follow-up investment." The average number of companies angels indicated they invested in was two per year. One angel said they had invested in six high-tech start-ups. This angel was from Ice Angels, the biggest angel group in New Zealand, therefore this large number could be explained due to the fact that Ice Angel sees 
Page 33 of 97

more deals than other networks. One angel indicated that some angels are driven by the rule of thumb metrics in terms of how many investments they do annually, for example one such metric used states you must invest in at least ten companies before having any success. Angels had said the amount of shares they would ask for from a high-tech start-up at first round depended on the evaluation of the business. Angels want to know that the evaluation is reasonable to the amount they are putting in.

\subsubsection{Sectors angels usually invest in}

All angel investors said there was no deal they would completely avoid based on the sector that it falls into, but there were definitely sectors that they preferred. The most common sectors that angels preferred were high-tech start-ups, start-ups with technology, four of the angels indicated that they invested in these sectors. One of those four angels gave the reason for this as "because they have better prospects of scaling quickly". Also products from the biotechnology sector seemed popular; three angels interviewed mentioned this sector. One angel mentioned that they try to avoid retail, property, and entertainment sector investments as they do not have the growth characteristics. Two angels indicated that they do not prefer pharmaceutical drugs because of the usual time it takes for such products to get to market. All angels interviewed prefer to invest in things they understood and had experience in, and stayed away from sectors that they had limited knowledge and interest in.

\subsubsection{Benefits of angel investors}

All angels mentioned that angels provide money but most importantly also bring experience and connections. One angel said, "Usually start-ups don't have these things therefore it is great value." One angel mentioned angels can be good mentors if they have experience in starting a company, that angel stated, "Mentors can coach the entrepreneurs through what is coming next because they probably can see two-three steps ahead to what's coming next." Two angels mentioned that angels can help access markets. One angel mentioned that angels can potentially help the company make more money than if they were to go alone. Another angel mentioned that angels can bring an immense amount of value and often at a relatively low cost - that angel said, "In some cases angels bring wisdom and opportunities." 


\subsection{Angel investor advice on how to find an angel investor}

\subsubsection{How to find informal investors}

The literature suggested finding informal angels is a difficult task, all angels in my study agreed this was the case therefore gave some good tips to help entrepreneurs find informal angels. Four of the angels suggested looking at the industry the company is operating in and speaking with people in that industry. One of those angels said, "This way someone may refer you to particular angels that have an appetite in that sector," another angel said, "Most informal angels have a preference for a certain industry." Two angels recommended using the media, one of those angels said it was important that entrepreneurs do not disclose their full idea or information that may harm a firm's intellectual property protection. An interesting quote found from my study, "If your idea is good; angels will contact you."

One angel advised gaining connections early, moving in circles where investors are, for example business clubs. One investor mentioned networking in the sector you are in and finding people who have developed things, that angel said, "They may not be able to help you personally but may point you into the right direction." One angel recommended looking at some recent exits in your area, finding people that were on the company board that might have some money to invest. Another angel suggested finding a professor or someone at a university who is knowledgeable in your area. That angel also recommended start-ups look in the business section of a local paper to find appropriate contacts that may be valuable.

\subsubsection{How to find the best fitted formal angel investors}

Finding an angel investor is one thing but finding one that is best suited for your start-up is also very important. Angels in my study mentioned pointers for finding the best investor for a start-up.

Five angels mentioned the importance of networking. One angel said that entrepreneurs should "talk to the person in charge of running the angel investor group and ask them to help find the right people for your start-up". One angel said that "entrepreneurs need to find who the investors are in your community and to understand that it will be a relationship built highly on trust". Two angels mentioned the importance in finding an angel group close to your location, especially if you are looking for ongoing engagement with your angel investor. 
Page 35 of 97

One angel stated that there are certain groups that are better at certain types of deals because they are more familiar with certain deals than other groups. One angel stated, "If you consider enterprise angels, they are good with anything that is growth, example agriculture. If you have anything to do with that, it will be in your best interest to go to them first. If you are a company that focuses in the film industry, contact Wellington angels, they have the best experience and connections. Wellington angels have done a number of deals in this sector." Another angel gave some great advice, "Learn to handle rejection; do not let one rejection stop your journey."

\subsection{Conclusion of findings chapter}

Information in this chapter is very insightful, it helped me gain a better understanding about the New Zealand angel investment market and most importantly it identifies the key things New Zealand angels recommend high-tech start-ups have in place before approaching angel investors. The chapter also recommends programmes for companies to approach and states angel investors' personal advice that could help high-tech start-ups become investment ready. In the next chapter, I will evaluate our start-up, "Auti", based on this information and then give implementation recommendations on what we still need to do in order to be in a better position to gain angel investment. 
Page 36 of 97

\section{Chapter 5 - Conclusion}

\subsection{Summary}

This thesis provided a reflection on my research into funding sources. My objective for looking into funding sources was to find the best suited funding sources for high-tech firms in New Zealand, such as "Auti", which I could then recommend to "Auti" to implement to help it become a sustainable business. Examining the capital structure from an early stage will help decrease the chances of "Auti" failing due to funding reasons.

The thesis covered the two-sided research that I conducted. Action-based research influenced the funding sources that I recommended our start-up, "Auti", implement. Research made me aware of different funding sources available, which I then investigated. The outcome of my research influenced my decision towards recommending a funding source or not. It is important for me to mention that although my research led me to make funding implication recommendations for "Auti", I am not the project champion, Helen is; therefore, the extent to which my recommendations will be implemented is out of my hands. The second type of research used was in-depth interviews. I conducted these interviews with angel investors in New Zealand to gain in-depth knowledge of the angel investment industry in New Zealand in the year 2014. It was action research into funding options that led to further investigation of angel investment therefore leading to the use of the second research method.

\subsubsection{Findings which support the literature}

My research into the angel investment industry in New Zealand confirmed a number of my findings from the literature.

Firstly, the idea that the angel investment industry is growing significantly, due to the industry becoming less secretive and more structured (Ibrahim, 2008). The literature suggested Auckland had the highest number of deals made annually in New Zealand (NZVCF, 2014). This statement was supported through my research, an angel (from Ice Angel in Auckland) said that he invested in at least six high-tech companies a year, which is significantly higher than the average number of investments made by angels, my research indicated the average was two per year thus indicating more deals are made in Auckland. 
Page 37 of 97

My research also found that the most common sectors angels invested in were in technology and biotechnology. The main contributor to a deal being made or ignored was the individuals behind the product or idea and how they were perceived by angels. Angels in my study also mentioned that a great number of deals were made informally and those angels preferred to invest in areas of their own expertise. All these points were mentioned in a previous study (New Zealand Venture Investment Fund, 2007).

\subsubsection{Findings that did not support the literature}

NZTE's 2014 study indicated that there are angels who will consider a range of investment opportunities and others who invest in specific regions. My research showed a different finding, all angels interviewed said that they would never avoid a specific type of deal, although they had their preferences, they would always consider a deal. The same study also indicated that the pharmaceutical sector was one of the most common sectors for angels to invest in. This is a contrast to my research finding, two angels were very obvious about their dislike of pharmaceutical products.

\subsection{What my research found}

My individual research identified a number of things. The main finding was a checklist of things New Zealand angel investors in the year 2014 look for in high-tech start-ups before they would consider investing. This is a contribution to practice, as high-tech start-ups can use this checklist before approaching angel investors.

The personal views of angel investors on the angel investment industry in New Zealand in the year 2014 is a contribution to research as it provides updated data on the industry specifically from the personal view point of angel investors. For example my research has numerous quotes from angels that help gain a more in-depth understanding into the industry.

Next, my research helped add to previous studies' findings, for example NZTE (2014) suggested that the average number of deals had decreased from previous years. My research found that the reasons for this were angels are trying to spread their risk and the global financial crisis. There are statistics to show the average share amount taken by angels from high-tech firms in the first round of investment (NZVCF, 2014; New Zealand Venture Investment Fund, 2007). Although nothing I could find explained investors' reasoning behind the amount taken. My research found that the 
Page 38 of 97

amount of shares angels ask for from high-tech start-ups at the first round depends on the evaluation of the business.

\subsection{Angel investment implication recommendation}

The key aspects angels indicated they look for in high-tech start-ups before they would consider investing, as found from my research, our team have already got in place. Our start-up is at a much further stage than the idea stage, we have a strong start-up team with individuals from various backgrounds and experience. We are showing commitment by investing personal funds into the start-up, specifically the project champion who put in her own money to develop the prototypes of "Auti" and has worked on the project for over a year without pay (refer to Appendix A). With regards to intellectual property, because the project champion had displayed "Auti" at a trade show, as well as displaying information about "Auti" online before attaining any intellectual protection, we decided that it was necessary to put a great deal of time and effort into finding the best intellectual property strategy for "Auti" (to view our full IP strategy please refer to Appendix D). Our business plan covers all aspects angels had indicated they wanted to see. We also have a number of "Auti" beta versions created, which we have started testing with our target audience.

The checklist established by findings in my research influenced me to recommend our team to implement a number of things on the checklist that could potentially help us gain angel investment. Firstly, we need to create stress testing, this is important as the product is targeted at children with autism who are known to often throw things (Wilson, 2010).

Secondly, we had not set enough time aside to sort out the company's financial documents. We do not have past financial documentation as we have not yet begun trading. It would still be beneficial to have financial documentation ready to show potential angel investors a breakdown on how funds were managed, also to create a detailed document showing what we would need angel funding for.

\subsubsection{Other funding sources implication recommendations}

Although we have chosen angel investment, which is equity funding, as our main funding source, my research findings into funding sources has lead me to make the following recommendations with regards to what start-up funding we should implement into "Auti".

First of all, I would recommend that we implement peer-to-peer lending, which falls into debt funding, for four main reasons. It has been indicated that gaining angel investment often can be a 
Page 39 of 97

long process (Ice House, 2013), therefore I would recommend implementing peer-to-peer lending, once it becomes legal in New Zealand in July 2014, before applying for angel investment. Secondly, as we are a high-tech product, we will need to develop a number of prototypes and conduct numerous tests before "Auti" can enter the market, thus the need to gain as much funding as possible. Thirdly, as peer-to-peer lending is debt lending, we would not be concerned with losing control or equity, which is something our team wants to keep a tight control over, these reasons for selecting debt equity support the findings done on Italian firms (Guidici \& Paleari, 2000). My research had indicated that having external funding before approaching angels can be seen as a signal of commitment therefore peer-to-peer funding could not only gain funding but act as a stepping stone to gaining angel investment.

\subsection{Auti's capital structure}

Funding that we have already used has been internal funds, which supported numerous studies' conclusions that high-tech firms' primary source of funding comes from people within the start-up (Manigart \& Struyf, 1997; Moore, 1994; Guidici \& Paleari, 2000; Columbo \& Grilli, 2007; Empirical Study in Denmark, 1997). Therefore, based on the internal funding we used, and including the two funding sources I have recommended we implement, and the order in which I recommend we implement them, I can conclude that "Auti's" capital structure follows the pecking order capital structure theory, therefore the answer to research question three is that high-tech firms in New Zealand follow the pecking order capital structure theory.

\subsection{Limitations and recommendations}

The purpose of my individual interview research was to get a better understanding of the angel investor industry in New Zealand in the year 2014. The angel investment industry includes both formal and informal investment. Due to the fact that only one informal angel investor was interviewed in my research, this limits my research in terms of how accurately the findings support informal angel investment activity in New Zealand. Therefore I would recommend that further research be conducted focusing on interviewing informal angels in New Zealand.

Because of time constraint, I was not able to interview angels from each formal network in New Zealand therefore I would recommend that further research is conducted that includes interviewing an angel from each network in order to support findings for all formal networks within New Zealand. Some of the questions in my interview got similar answers from all angels that had been 
Page 40 of 97

interviewed. Repetition of these answers gives me confidence in generalising those answers to the majority of formal angels in New Zealand.

My thesis looked to answer thesis question three, "how relevant is the 'Pecking order capital structure' theory to high-tech start-up companies in New Zealand?" Based on the capital structure of our start up, "Auti", which - in terms of research - is only one case study used to check a theory against, therefore this is counted as a major limitation. We cannot generalise the findings of "Auti"'s capital structure to all high-tech start-ups in New Zealand. Further research needs to be conducted to evaluate a number of high-tech start-ups' capital structures in New Zealand. Also specific focus needs to be done to investigate the reasons behind high-tech start-ups' funding choices. There was, however, one obvious advantage of using our own start-up to evaluate high-tech start-ups' capital structure, this was that it gave me an in-depth analysis into our company's capital structure. My ongoing participation in the start-up allowed my research to include all factors that influence the capital structure, which led to full disclosure that less engaging methods of data acquisition would not allow.

My interview questions were specific to high-tech start-ups therefore further research needs to be conducted to identify a checklist of things angel investors look for before they would consider investing in all types of start-ups, not just high-tech firms. Another limitation is that I had only interviewed angels in New Zealand. I would also recommend that further research is conducted overseas on high-tech firms, which can then be compared to my findings. This could be very insightful for New Zealand high-tech firms, especially those looking to enter foreign markets and gain angel investment in those markets. 


\section{References}

AANZ (2014). About us. Retrieved from http://www.angelassociation.co.nz/about-us/ Allen, F., Qian, J. \& Qian, M. (2005).Law, Finance, and Economic Growth in China. Journal of Financial Economics, 77, 57-116.

Analysing Interview data. (2011). Retrieved from https://www.utexas.edu/academic/ctl/assessment/iar/programs/report/interviewAnalysis.php

Anders, I. (2006) .Studies on the venture capital process. Umea School of Business, Umea University. Retrieved from http://umu.diva-portal.org/smash/get/diva2:144734/FULLTEXT01.pdf

Atherton, A. (2009). Rational actors, knowledgeable agents: extending pecking order considerations of new venture financing to incorporate founder experience, knowledge and networks. International Small Business Journal, 27(4), 470-495.

Bacova, E. (2014). Why Rippr Crowd Loyalty intends to use equity crowd funding. Retrieved from http://www.snowballeffect.co.nz/why-rippr-crowd-loyalty-intends-to-use-equitycrowdfunding

Baty, G. \& Sommer, B. (2002). True then, true now: A 40-year perspective on the early stage investment market. Venture Capital, 4(4), 289-293.

Bhide, A. (1992). Bootstrap Finance - The Art of Start-ups. Harvard Business Review, 70, 109-117.

Biernacki, P., and Waldorf, D. (1981).Snowball sampling: Problems and Techniques of Chain Referral Sampling. Sociological Methods and Research, 10,141-63

Bogdan, B. \& Bilklin, K. (3rd Eds). (1998).Qualitative Research for education: An Introduction to Theory and Methods. Needham Heights, MA: Allyn and Bacon.

Boyce,C.\& Neale,P.(May,2006).Conducting in-depth interviews: A guide for designing and conducting In-Depth Interviews for evaluation input. Pathfinder International, 2,(1) .Retrieved from http://www.cpc.unc.edu/measure/training/materials/data-qualityportuguese/m_e_tool_series_indepth_interviews.pdf

Bruno, V. \& Tyebjee, T. (1985). The Entrepreneur's Search for Capital, Journal of Business Venturing, $1(1), 61-74$.

Buysere,K.,Gajda,O.,Kleverlann,R.\&Marom,D.(2012).A Framework for European crowd funding.

Carr, W. \& Kemmis, S. (1986). Becoming Critical Education, knowledge and action research. Falmer.

Cassar, G. (2004).The financing of business start-ups. Journal of Business Venturing, 19(2), 261-284.

Cavanagh, S. (1997).Content analysis: concept, methods and applications. Nurse Researcher, 4(3), 5 16. 
Charles, M. (2 ${ }^{\text {nd }}$ Eds). (1995). Introduction to educational research. San Diego, Longman.

Cheng, P. (March, 2008) Quasi Equity.18-20 St Andrew Street, London EC4A 3AY UK: Charities Aid Foundation. Retrieved fromhttps://www.cafonline.org/pdf/VenturesomeQuasiEquityMarch2008.pdf

Colombo, G. \& Grilli, L. (2007). Funding Gaps? Access to Bank Loans by High-Tech Start-Ups. Small Business Economics, 29, 25-46.

Coolican, H. (2nd Ed). (1994). Research methods and statistics in psychology .London: Hodder \&Stoughton.

Creswell, W. (1998). Qualitative inquiry and research design: Choosing among five traditions. Thousand Oaks: Sage Publications.

Creswell, W. (2nd Eds). (2005). Educational Research. Planning, Conducting, and Evaluating Quantitative and Qualitative Research. Upper Saddle River, USA: Pearson Education.

Denzin, K. (2nd Eds). (1989).Interpretive interactionism .Thousand Oaks, CA: Sage.

Denis, J. (2004). Entrepreneurial finance: An overview of the issues and evidence. Journal of Corporate Finance, 10, 301-326.

Dick, B. (1992). Qualitative action research: improving the rigour and economy. Brisbane: Action Learning, Action Research and Process Management Association.

Dillman, D., Sangster, L., Tarnai, J. \& Rockwood, H. (1996).Understanding Differences in Peoples Answers to Telephone and Mail Surveys. In Braveman, M. \& Slater, J (Ed.), Advances in Survey Research (pp. 70-110).San Francisco: Jossey-Bass, Inc.

Edmonds,E., Bilda,Z., Costello,B., Leggett,M., SarahMoss, Muller,L., Phalip,J., Turner,G.\& Zhang,Y.(November,2006).Practise Based Research: A guide. Creativity and Cognition Studios, 1.Retrived from http://www.mangoldinternational.com/fileadmin/Media/References/Publications/Downlo ads/Practice_Based_Research_A_Guide.pdf

Empirical Study in Denmark. (1997). International Journal of Management, 20(4), 535-547.

European business angel network code of conduct. (2014) .Retrieved from http://www.eban.org/wp-content/uploads/2013/01/EBAN-Code-of-Conduct.pdf

Feldman, M. (1992). Constructive processes in Survey research: Explorations in Self-Generated Validity. In Schwarz, N. \& Sudman, S (Ed.), Context Effects in Social and Psychological Research. New York: Springer-Verlag.

Fenn, W., N, Liang. \& S, Prowse. (1995). The Economics of the Private Equity Market. Washington: Board of Governors of the Federal Reserve System.

First to market. (2014). Retrieved from http://www.netlingo.com/word/first-to-market.php 
Fiti, T., Markovska, V., Bateman M. (2007). Pretpriemnishtvo. (Entrepreneurship), 2nd Edition. Faculty of Economics.

Foddy, W. (1993). Constructing Questions for Interviews and Questionnaires: Theory and Practice in Social Research. Cambridge: Cambridge University Press.

Fontes, M. \& Coombs, R. (2001).Contribution of new technology-based firms to the strengthening of technological capabilities in intermediate economies. Research Policy, 30, 79-97.

Fox, N. (2006).Using Interviews in a research project. The National Institution for Health Research RDS for the East Midlands .Yorkshire \& Humber.

France angels. (2004), Business Angels Survey 2003(Exact citation unknown).

Frank, Z. \& Goyal, K. (2003). Testing the pecking order theory of capital structure. Journal of Financial Economics, 67, 217-248.

Freear J., Sohl, E. \& Wetzel, E. (1995). Who Bankrolls Software Entrepreneurs? In Bygrave, D., Bird, J., Birley, S. et al. (ed), Frontiers of Entrepreneurship Research Babson College: Wellesley, MA.

Freear, J., Sohl, E., \& Wetzel, W. (2002). Angles on angels: Financing technology-based ventures - a historical perspective. Venture Capital, 4(4), 275-287.

FRST grants. (May, 2008) Retrieved from http://www.youtube.com/watch?v=IYSw_CEux6E

Galloway, I (August, 2009). Peer-to-Peer Lending and Community Development Finance. Centre for Community Development Investments, Federal Reserve Bank of San Francisco. Retrieved from http://www.frbsf.org/community-development/files/wp2009-06.pdf

Gilmore, T., Krantz, J. \& Ramirez, R. (1986) .Action Based Modes of Inquiry and the Host-Researcher Relationship. Consultation, 5.3.

Goff, S. (July 2012).Sustainable Banking and Finance. Retrieved from http://www.ft.com/cms/s/0/bb517d8a-a5ad-11e1-a3b400144feabdc0.html\#axzz32W2bMy8u

GRANT finder Ltd. ('n.d.'). Special Update feature: A beginning guide to successfully securing grant funding . Retrieved from http://www.grantnet.com/HelpfulReports/securingfunding.pdf

Graftton, C. \&Jones, I. (end Ed). (2010).Research Methods for sports Studies .New York: Taylor \&Francis.

Guidici, G. \& Paleari, S. (2000). The Provision of Finance to Innovation: A Survey Conducted among Italian Technology-based Small Firms. Small Business Economics, 14 (1), 37-53.

Hann, L. \& Hinloopen, J.(1999). Dept or equity? An empirical study of security issues by Dutch companies. Econometric research and special studies department, 577.Retrieved from http://ideas.repec.org/p/dnb/wormem/577.html 
Hall, G., Hutchinson, P. \& Michaelas, N. (2004) .Determinants of the capital structures of European SMEs. Journal of Business Finance and Accounting, 31 (5/6), 711-728.

Harrison, T,. Mason, M. \& Girling P. (2004). Financing bootstrapping and venture development in the software industry .Entrepreneurship and Regional development, London: Routledge.

Henry,B.,Moffitt, E.,Caspi,A.,Langley,J.\& Silvia,P (1994).On the Remembrance of Things Past: A Longitudinal Evaluation of the Retrospective Method.Psychological Assessment 6(2),92101.

Ibrahim, M. (2008).The Not So Puzzling Behaviour of Angel Investors. Vanderbilt Law Review, 61(0716).

Icehouse. (2014).About us. Retrieved from http://www.theicehouse.co.nz/about-us/

Ice house. (2013). "Mentioned in the workshop". Deep dive into start-up capital, 2013 workshop. Wellington, New Zealand

Intuit. (2013).Bridging the gap. Retrieved from http://intuitglobal.intuit.com/delivery/cms/prod/sites/default/intuit.ca/downloads/quickb ooks/bridging_the_gap.p

Joppe, M. (2000).The Research Process. Retrieved February from http://www.ryerson.ca/ mjoppe/rp.htm

Johnson, R. (1997).Examining the validity structure of qualitative research.Education, 3,282-292.

Kleemann, G., Voss, G. \& Rieder, K. (2008). Underpaid Innovators: The Commercial Utilization of Consumer Work through Crowdsourcing. Science, Technology \& Innovation Studies, 4(1), 5 26.

Kolb, D. (1984).Experiential learning: experience as the source of learning and development. Englewood Cliffs.

Kvale, S. (1996). Interviews: An Introduction to Qualitative Research Interviewing. Thousand Oaks, CA.

Lambert, T. \& Schwienbacher, A. (2010). An Empirical Analysis of Crowdfunding. Retrieved from http://ssrn.com/abstract $=1578175$

Lancaster, A., Dodd, S. \& Williamson, R. (2004). Design and analysis of pilot studies: recommendations for good practice. Journal of Evaluation in Clinical Practice 10(2), 307312.

Laranja, M. \& Fontes, M. (1998).Creative adaptation: The role of new technology based firms in Portugal. Research Policy, 26, 1023-1036. 
Page 45 of 97

Lead investor. (2014).Retrieved from http://www.cfpartners.com/lead-investor.aspx

Lehnen, G. \& Reiss J. (1978). Response Effects in the National Crime Survey.Victimology, 3,110-160.

Lewis, M. (2nd Eds). (2008).Emerging life science companies Freedom to operate. Retrieved from http://www.morganlewis.com/documents/erh/erh_freedomtooperate_elscdeskbook.pdf

Lingard, B. (2008). Globalising research accountabilities .ACCESS, 27(1/2), 175-188.

LinkedIn (2014). About us. Retrieved from http://www.linkedin.com/about-us

Little, D. (1977). New Technology Based Firms in the UK and the FRG. Wilton House Publications, London.

Mackie, J. (2004). Confidence returns as UK backs enterprise. International Financial Law Review, 2004 Supplement, 71-72.

Manigart, S. \& Struyf, C. (1997). Financing High Technology Start-ups in Belgium: An

Exploratory Study. Small Business Economics, 9,125-135.

MBIR. (2014.).Get funded. Retrieved from http://www.msi.govt.nz/get-funded/

McKaskill, T. (2009, July 1). An introduction to angel investing - a guide to investing in early stage entrepreneurial ventures. Retrieved from

http://angelresource.org|angelresourceinstitute.org|www.angelresource.org|www.angelr esourceinstitute.org/resource-center/an-introduction-to-angel-investing.aspx.

Michaelas, N., Chittenden, F. \& Poutziouris, P. (1999). Financial policy and capital structure choice in U.K. SMEs: Empirical evidence from company panel data. Small Business Economics, 12, 113-130.

Ministry of Economic Development. (2007).Baseline Review of Angel Investment in New Zealand. Wellington. Retrieved from https://www.med.govt.nz/aboutus/publications/publicationsby-topic/evaluation-of-government-programmes/archive/report.pdf

Moore, B. (1994).Financial Constraints to the Growth and Development of Small HighTechnology Firms. In: D.J. Storey and A. Hughes (Eds.), Finance and the Small Firms. New York: Routledge.

Morissette, S. (2007).A profile of angel investors. Journal of Private Equity, 10.3.

Myers, C. (1984).The Capital Structure Puzzle. The Journal of Finance, 39(3), 575-592.

Myers, S. \& Majluf, N. (1984). Corporate financing and investment decisions when firms have information that investors do not have. Journal of Financial Economics, 13(2), 187-222.

New Zealand venture Capital association (2014) .Young Company finance report .Retrieved from 
http://www.nzvca.co.nz/content/Young_Company_Finance_Issue_16_April_2014.pdf

New Zealand Venture Investment Fund. (2007). The business of Angel investment in New Zealand: A guide. Retrieved from http://www.nzvif.co.nz/documents/publications/Business_of_Angel_Investing_in_NZ_Gui de.pdf

Nofsinger, J. \& Wang, W. (2009). Determinants of Start-up Firm External Financing Worldwide. Washington State University College of Business: Pullman. Retrieved from http://www.clevelandfed.org/research/Conferences/2009/3-12-2009/Nofsinger_Wang.pdf

Northrup, A. (1997).The Problem of Self Report in Survey Research. North York, Ontario, Canada: Institute for Social Research.

NZTE.(2009).Essential guide for growing your business and obtaining Seed: Investment ready guide. Wellington. Retrieved from http://www.angelassociation.co.nz/content/downloads/Documents/investment-readyguide.pdf

NZTE. (2014).About us. Retrieved from https://www.nzte.govt.nz/en/about-us/

NZVIF. (2014).Seed Co Investment Fund. Retrieved from http://www.nzvif.co.nz/seed-coinvestment-overview.html

NZVCF. (2014).Young Company Finance .Retrieved from http://www.nzvca.co.nz/library/industryreports-a-research/young-company-finance/192-young-company-finance/

O'Brien, R. (2001).An Overview of the Methodological Approach of Action Research. In Richardson, R (Ed.) Theory and Practice of Action Research. João Pessoa, Brazil: Universidade Federal da Paraíba. Retrieved from http://www.web.ca/ robrien/papers/arfinal.html

OECD. (2010). Capital Structure: Some Legal and Policy Issues, OECD Publishing. Retrieved from http://www.oecd.org/daf/ca/corporategovernanceprinciples/1857283.pdf

OECD. (2011). Financing High-Growth Firms: The Role of Angel Investors, OECD Publishing. Retrieved from http://dx.doi.org/10.1787/9789264118782-en

Parkinson, G. \& Drislane, R. (2011). Qualitative research. In Online dictionary of the social sciences. Retrieved from http://bitbucket.icaap.org/dict.pl

Patton, Q. (2nd Eds). (2001). Qualitative evaluation and research methods. Thousand Oaks, CA: Sage Publications, Inc.

Patton, Q. (3rd Eds). (2002).Qualitative research and evaluation methods.Thousand Oaks, CA: Sage.

Peters, B. (2010). Early Exits - Exit Strategies for Entrepreneurs and angel Investors. 
Preston, S. (2007). Angel Financing for Entrepreneurs: Early-Stage Funding for Long-Term Success. San Francisco, CA: Jossey-Bass.

Reiling, H. \& Pollard, M. (Feb, 09, 1999). Debt vs Equity: Definitions and Consequences. Retrieved from http://hbr.org/product/Debt-v--Equity--Definitio/an/299041-PDF-ENG

Ross, S., Westerfield, R. \& Jordan, B. (2002).Fundamentals of corporate finance. The McGraw-Hill Irwin.

Scott, S. (2009). Fool's Gold? The Truth behind Angel Investing in America. New York: Oxford University Press.

Shyam-Sunder, L. \& Myers ,C. (1999).Testing static tradeoff against pecking order models of capital structure. Journal of Financial Economics, 21, 219-244.

Smith, R. \& Smith, J. (2nd Eds). (2003).Entrepreneurial Finance.

Snowball Effect. (2014). What is crowd funding. Retrieved from http://www.snowballeffect.co.nz/about-us

Sohl, J. (1999). The Early Stage Equity Market in the USA, Venture Capital. An international Journal of Entrepreneurial Finance, Routledge, part of the Taylor \& Francis Group, (1/ 2), 101-120.

Sohl, J. (2011).The angel Investor Market In 2010: A market on the rebound, Ctr. for venture research.

Spann, M. \& Adams, M. ('n.d.'). Seed Funding for high technology ventures: The Role of the Bridge Business. University of Alabama in Huntsville. Retrieved from http://www.sbaer.uca.edu/research/asbe/1998/text/98asbe085.txt

Tandon, R. (1996). The historical roots and contemporary tendencies in participatory research: implications for practise. In Koning K, Martin M (Ed.), Participatory research in health: issues and experiences (pp.19-26). Zed Books.

Taylor, J. \& Bogdan, R. (1984). Introduction to Qualitative Research Methods. New York: Wiley Interscience.

Townsend, S. (May, 2014).Equity Crowdfunding Remains Stalled; New Legislation Introduced in Congress. Retrieved from http://www.mondaq.com/unitedstates/x/315722/Venture+Capital/Equity+Crowdfunding+ Remains+Stalled+New+Legislation+Introduced+in+Congress

Vaughan, G (May, 2014). Peer-to-peer lending start-up Harmoney. Retrieved from http://www.interest.co.nz/business/69995/peer-peer-lending-start-harmoney-names-robcampbell-chairman

Verheul, I. \& Thurik, R. (2001) .Start-up capital: does gender matter? Small Business Economics, 16 (4), 329-346. 
Page 48 of 97

Wadsworth, Y. (Nov, 1998). What is participatory action research? Action Research International Paper. Retrieved from http://www.scu.edu./schools/gem/ar/ari/pywadsworth98.htm

Wilson, D. (March, 2010).New ways to teach children with Autism. Retrieved from http://www.nationalautismcenter.org/pdf/boston_parents_paper_puzzling_through.pdf

Winborg J. \& Landstrom, H. (2001). Financial Bootstrapping in Small Businesses: Examining Small Business Managers' Resource Acquisition Behaviours. Journal of Business Venturing, 16, 235-254.

Wong, A. (2002).Angel finance: The other venture capital. Graduate School of Business, University of Chicago. 
Page 49 of 97

\section{Appendix A - Auti's Case Study}

Contents page:

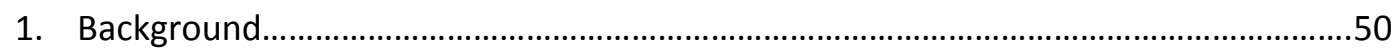

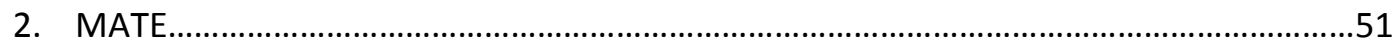

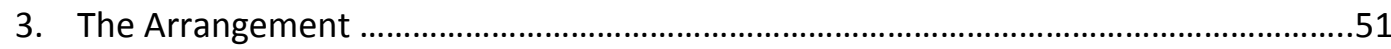

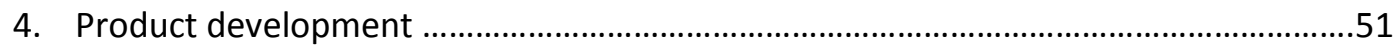

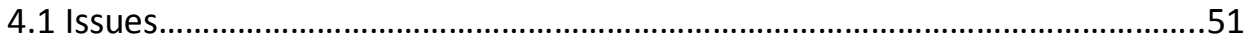

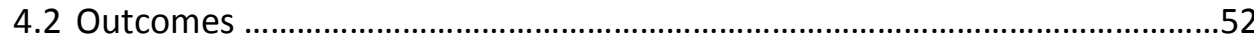

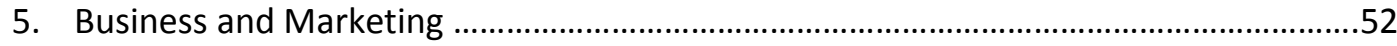

5.1 Issue

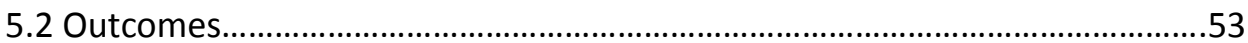

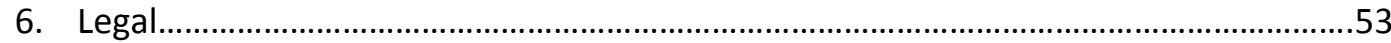

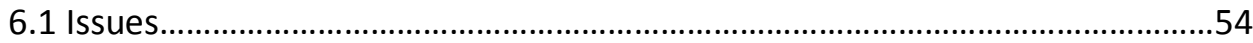

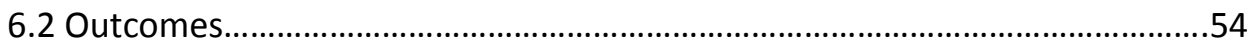

7. End of year progress summary and business proposition..............................................54

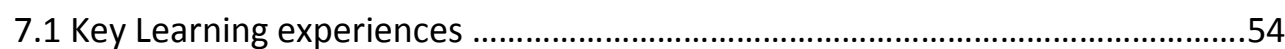

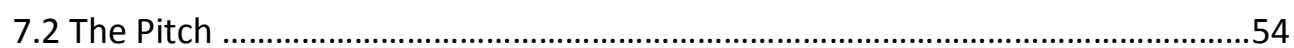

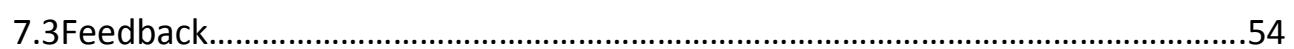

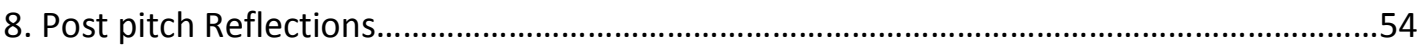




\section{Background}

The project began in an undergraduate university course where a student (the project champion) excelled in an assignment by creating the original prototype toy.

The toy was designed for the purposes of helping children with Autism. The project champion's vision was that the toy would be a social behaviour development tool for these children. The idea was simple, but seemed to have potential and generated a lot of interest very quickly. So much interest in fact, that Victoria University offered the project champion the opportunity to take the Masters in Psychology programme. One of the core things she would do in this programme is test the effectiveness of her invention by running some trials with a number of autistic children.

The project champion became understandably excited about her invention and the fantastic opportunity offered to her by the university and so she went online. She began to post blogs about her idea and put up photos and videos of the prototype. This quickly generated even more interest, particularly from the Autism community. She then displayed the prototype at a public exhibition in order to confirm the potential of the invention.

With all of this attention, it soon became apparent that the toy could have some real commercial potential. This meant that the prototype was potentially worth developing into a product. The project champion approached a Masters level electric engineering student to help her develop the prototype. This student has been involved in the project ever since.

However aside from product development, the project required a business and marketing plan. The project champion also later realised that she had potentially made a mistake from a legal standpoint by posting pictures and information of her invention online and by taking the prototype to an exhibition, prior to acquiring any type of legal protection. The project champion needed help in these areas of the project. Coincidently she then heard about the Masters of Advanced Technology Enterprise (MATE) programme.

\section{MATE}

The MATE programme is a course which was run for the first time in 2013 , by Victoria University. The programme is available to post graduate students from different backgrounds of study. These students are required to form teams around a project to which they can contribute value. 
Page 51 of 97

The project champion proposed the toy as a potential project. She prepared a short presentation in which she pitched the potential of her idea and asked for assistance.

Three students agreed to form a team to take on the project. One of these students was Anna Samoylova. Anna is an international business and marketing major and as such was the ideal candidate to take charge in relation to the business and marketing work. Vlad Samoylov is a law major, who naturally took on the legal aspects of the project. The final team member was Tiara Wan who was a bio-tech major. Tiara chose to be responsible for product development.

\section{The Arrangement}

When the project was first pitched to the MATE class, there was unanimous concern expressed by all students in relation to the lack of testing. The idea behind the prototype appeared innovative, but there was no proof that the toy would generate the desired response from the autistic children. Therefore, the project champion was asked whether it would be possible to do some initial testing with a small number of children at an earlier stage in the year. This initial testing would identify what features were successful and which features needed further developing. This information would help identify the minimum marketable product.

The project champion agreed to conduct the testing earlier, in order to establish what the minimum marketable product was and this agreement was the basis for the formation of the team.

\section{Product Development}

The toy has come a long way since the initial public disclosure. The product development team working on the project have produced a number of new features which did not exist at the time of the disclosure. However the success rate of these features is still unknown despite the initial agreement, as testing with the children has only recently commenced.

\subsection{Issues}

The product development team were unable to begin testing the product until a much later stage in the year as they encountered great difficulty finding test subjects, given the sensitive nature of the project. 
Page 52 of 97

The project champion did not want Tiara being involved in work relating to the product's development because it was an area of work that she chose to remain entirely in charge of. The project champion had already acquired assistance in this area of the project prior to addressing the MATE students. Therefore she now only required assistance in work relating to the business and legal aspects of the project.

\subsection{Outcome}

The toy is almost entirely complete in the sense that most features which were originally planned to be incorporated into the product, are now in place. However, due to the fact that testing was delayed, the success potential of the product at the current stage of development is still unknown.

The project champion did not want Tiara being involved in product development and testing. After some time, Tiara decided to resign from the project entirely.

\section{Business and Marketing}

Anna took charge in relation to the business and marketing aspects of the project. She began by conducting some thorough market research. After having completed her literature review, she wrote up question guides and surveys, which would be used in a series of interviews with therapists and parents of children with autism. She submitted these to the Victoria University Human Ethics Committee (VUHEC) for approval.

Anna was also prepared to go out and look for financial assistance for the purposes of expanding the product development team. She drew up a business plan and made arrangements to meet with potential investors.

\subsection{Issues}

The project champion was concerned that the interviews with the therapists and parents could be potentially detrimental to the project, if conducted by someone who was not well versed in psychology and who had limited knowledge about autism. Anna had conducted research on autism, but the project champion was nonetheless concerned that she would potentially offend the highly sensitive market by conducting these interviews. In fact due to a slight misunderstanding, the project champion believed that Anna had already conducted some interviews and that this had 
Page 53 of 97

contributed to the difficulty in finding willing test subjects. Of course, Anna did no such thing as she was still awaiting ethical approval and confirmation from the project champion herself.

Once the misunderstanding became resolved, the project champion informed Anna that she would take the surveys and interview guides and conduct the interviews herself at a later stage, as this was a very sensitive market and since she had more knowledge about autism.

The project champion did not allow Anna to approach investors because she felt that the product development team had developed some new intellectual property, which she did not want to disclose in exchange for financial assistance.

\subsection{Outcome}

Due to the very small size of the product development team, the toy took a long time to develop. Also the delay in product testing means that the toy's business potential is still unknown. Therefore the business plan accommodates in the best way possible, for a number of potential outcomes.

\section{Legal}

The primary task that lay before Vlad was to identify the legal ramifications of the prior public disclosure. After conducting an extensive literature review, Vlad was able to identify the Intellectual Property (IP) protection modes that were adversely affected by the disclosure. He then looked for exceptions and identified what had to be done in order to once again have the availability of these modes of protection.

Vlad then identified and advised the project team, including the project champion, about the effectiveness of the modes of protection that were available despite prior public disclosure. He also identified the protection modes, which the toy had potentially automatically acquired and advised the team about the benefits and limitations in relation to each of these.

At a later stage in the year, after examining Anna's market research, the team including the project champion agreed that a potential target market outside of New Zealand (NZ) could be the United States of America (US). Vlad then set out to examine US legislation and case law, in order to identify the US requirements for acquiring IP protection. He also identified some of the key differences between US and NZ protection measures. At around this time, Vlad received approval from the VUHEC to interview local manufacturing firms that sell their products overseas as well in NZ. These 
Page 54 of 97

interviews provided him with insight into IP protection measures that are taken by companies when operating in foreign markets.

Aside from investigating into IP protection, Vlad also examined product safety standards. He was able to identify the standards that were applicable to the toy and advised the team as to what had to be done in order to ensure that the standards were complied with.

\subsection{Issues}

Due to the product development team having not yet completed testing the newly developed features, it is still unknown whether they are generating the desired response from the children and are thus worthy of legal protection.

\subsection{Outcome}

Existing legal protection has been identified and a legal strategy has been produced for the foreseeable future. This is a strategy that can be implemented once testing is complete.

\section{End of Year Progress Summary and Business Proposition}

After several months the project team were asked to prepare a presentation which would summarise their progress and identify their key learning experiences. The team also chose to pitch a business proposition at the end of the presentation. The presentation was held before a panel of academics and experienced entrepreneurs.

\subsection{Key Learning Experience}

The key learning experience for the project team was experiencing the difficulty of finding willing test subjects when the product being tested strives to achieve a therapeutic benefit. In this case the toy aims at improving the social behaviours of children with autism. The difficulty primarily stems from parent's reluctance to test such a product on an autistic child. Parents are generally unwilling to subject their child to such testing until the product has gone through all the necessary ethical approvals and usually not until the testing is backed by therapists, or is conducted within the confines of official therapy sessions. 
Page 55 of 97

\subsection{The Pitch}

The team made a proposition to the project champion, recommending taking a shift in business strategy from the main vision in the short term in order to focus on developing a minimum marketable product. This proposition had been made to the project champion early on in the project, but after several months of market research the team were now even more confident that they had identified demand in the market for much simpler variants of the toy. The key difference is that these variants would not promise to produce any kind of therapeutic benefit, making it substantially easier to find test subjects and thus allowing the team to identify a minimum marketable product much sooner. The culmination of the necessary approvals and expert backing for the initially envisioned toy could continue to be acquired for the long run, while simpler products could be developed and marketed in the near future. These simpler products would in turn provide the much needed finance for further development of the envisioned toy.

\subsection{Feedback}

The panel of academics and experienced entrepreneurs provided feedback on the team's proposition to the project champion. The entire panel acknowledged that the clash between the team's proposition and the project champion's set vision for the product can be a serious obstacle in a business venture. They said that there comes a point in any business venture where it is up to each individual member to decide whether to agree with the vision and pursue it, or walk away from the project all together. The unanimous opinion of the panel was that it is probably worth pursuing the project vision despite the extensive delays because the toy has the potential to be such a good product. They said that the project addresses such a big societal issue that it is worth taking the long and tedious journey, even if it means only coming up with a very small part of the solution. Furthermore they explained that the time and effort that goes into all the testing makes it that much harder for any potential competitors to emulate the product.

\section{Post Pitch Reflection}

Since the presentation, the team have taken on board the feedback from the panel and have decided not to take the shift in business strategy for the sake of developing variant products, as these may have the effect of taking away from the reputation that they are trying to establish. The team is striving to become a business that produces products which are proven to be successful 
Page 56 of 97

therapeutic tools. In order to ensure that the toy lives up to its full potential all the necessary testing is currently being conducted. 
Page 57 of 97

\section{Appendix B - Auti's Business plan}

\section{Contents page:}

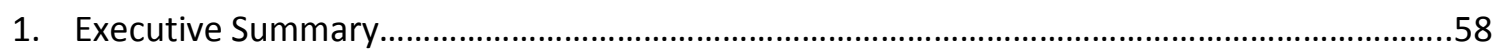

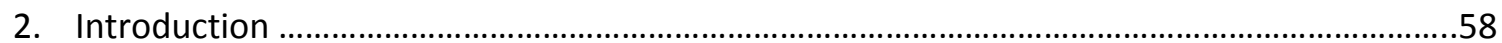

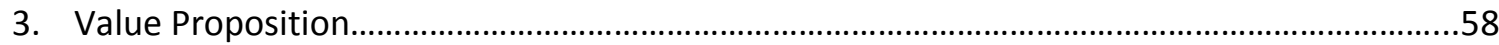

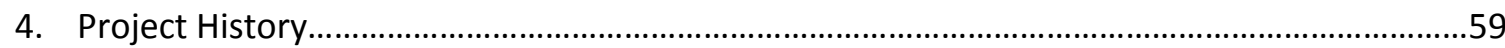

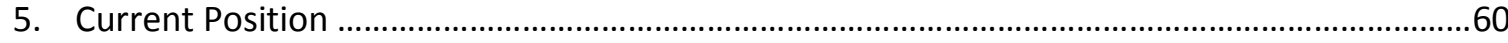

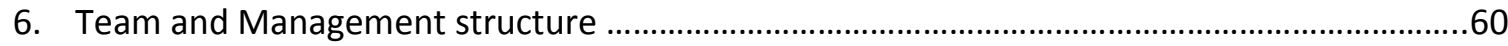

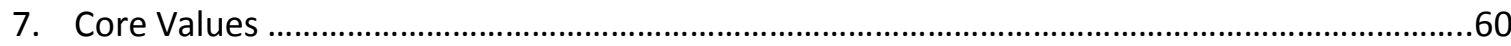

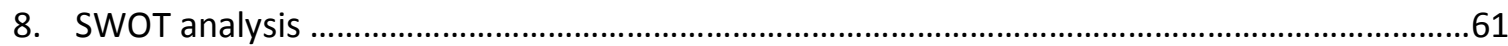

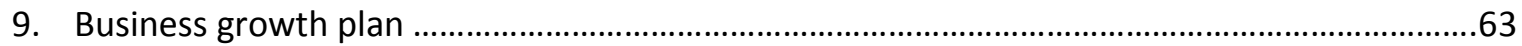

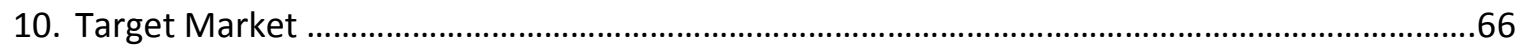

11. Tactical Promotional plan(Acquiring customers) …....................................................................68

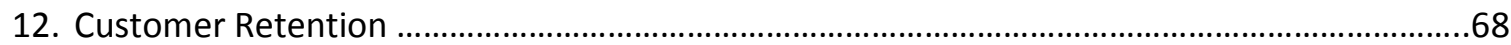

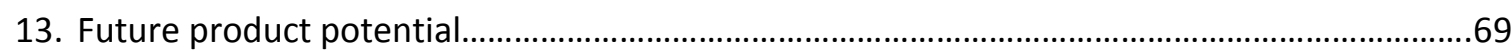

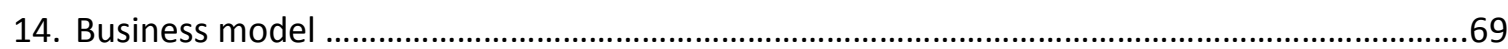

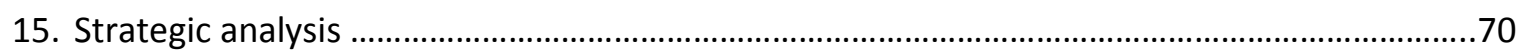

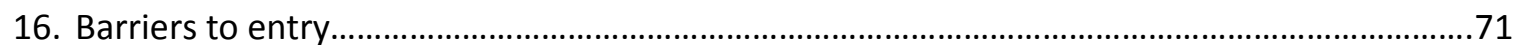

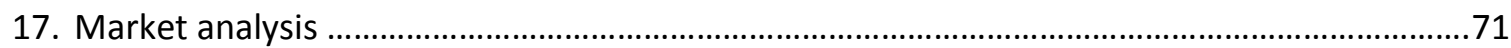

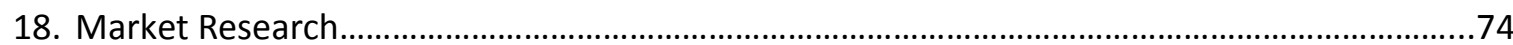

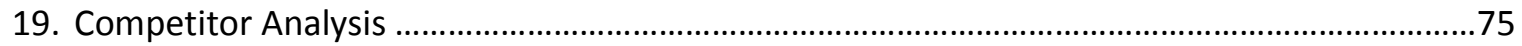

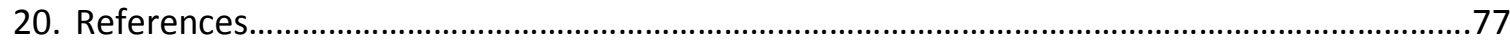


Page 58 of 97

\section{1 .Executive Summary}

The most feasible business strategy has been developed for 'Auti' to help it be commercialised and become a sustainable business.

There are a number of factors that influenced the overall business strategy. Firstly the constraint that the 'Auti' team faced of being asked to be product led by the project champion .Product led means entering the market with a particular product already in mind and looking for a problem to fix (Product led, 2013). Second factor was the findings from the market research which was conducted into the autism market. The final factor was the current position of 'Auti' such as its development stage and its intellectual property.

After careful market research the team decide to enter the US for a variety of reasons such as the US having a large 'Applied behaviour analysis' therapy market which we identified would be a great fit for 'Auti' because ABA therapy is one of the most effective therapies for teaching children with autism positive behaviour therefore 'Auti' could act as a tool which assists with ABA therapy.

The business plan evaluates the current position of 'Auti', looks closely into the US autism market and describes our chosen market entry mode into the US in detail including a marketing plan. It also pin points a number of additional problems in the Autism market that 'Auti' could fix.

\section{Introduction:}

'Auti' is a robotic, interactive toy designed to help teach children with autism positive behaviour. Both primary and secondary research indicated that there are a number of market segments with problems that Auti could address.

Market research also found two additional problems in the market that 'Auti' could help with:

1) Lack of respite care for autism.

2) Children with autism find it hard to transition from home to school.

\section{Value Proposition:}

The vision for the completed 'Auti' is to become a successful social behaviour development tool for children with autism. 


\section{Project History:}

The Product 'Auti' was originally created by Helen Andreae as part of her honours research in 2012. At that stage she had created a prototype of the toy which could be controlled with a remote control. Aside from Helen, a Masters level electric engineering student is also working on product development. In 2013 Anna Samoylova and Vlad Samoylov joined the project. Throughout the year 2013 the following milestones were achieved by each member of the team:

Anna Samoylova (Business strategist for 'Auti)

- Market Research/validation

- Primary Research: Talked to twenty therapists and fifteen parents from the US and New Zealand.

- Secondary Research: Reading past research, articles and books

- A global scan: Conducted a SWOT and PEST analysis into foreign countries to identify the best international markets to enter.

- Created and evaluated alternative business strategies to find the most applicable one.

- Selected the best fit business strategy/plan.

- Conducting primary and secondary research into the funding resources available to high tech start-ups in New Zealand for two reasons. To become financially literate because this is a critical aspect for a start-ups growth (Webber \& Tether, 2007). Also to evaluate which funding resources would be most applicable for high tech companies such as our-selves.

Helen Andrea (CEO, Product Developer)

- Tested 'Auti' with a number of children with autism. Testing indicated aspects of 'AUTI' that either needed changes or needed to be removed.

- Initial planned version for 'Auti' with all its important parts is nearly completed.

Vladimir Samoylov(Legal Aid for Auti|)

- Identified IP protection that was affected by prior public disclosure.

- Identified existing IP protection.

- Identified US IP requirements.

- Identified applicable product safety standards.

- Set out future legal strategy. 


\section{Current Position:}

Currently we are focusing on a number of tasks which include:

- Completing initial testing with children with Autism in New Zealand.

- Searching for appropriate angel investors in New Zealand that we want to approach.

- Conducting due diligence on potential angel investors.

- Perfecting 'Auti's movements.

- Creating a strategy to best approach our chosen joint venture partner 'Interbots'

- Networking to find people to join our advisory board for example members of 'Autism New Zealand Inc'

\section{Team and management structure:}

1. Helen Andreae is the project champion as well as the CEO of the company. Her main responsibilities include managing product development and testing the product.

2. Anna Samoylova is the business and marketing strategist of the company. Her responsibilities include conducting marketing research/validation, creating and evaluating alternative business plans in order to find the most applicable plan, establishing partnerships, marketing and other growth strategies.

3. Vlad Samoylov is the Legal advisor for the company. His responsibilities surround everything to do with the legal aspect of 'Auti.

\section{Core Values}

The core values that underline 'Auti' is a key part in building long-term business success, how they will benefit customers and how they will help to motivate staff members. Our values make up the word CPIER

Caring:

-Caring for our customer's pre, during and after a sale.

-Treating customers more like family rather than customers.

Passion: 
Page 61 of 97

-Being excited and driven to work for 'Auti'.

-Having a sense of love for the company.

Innovation:

-Differentiating through creating innovative features.

-Sharing ideas and knowledge with each other through teamwork.

-Continuously asking what next?

Excellence:

-Bring your very best to the company.

-Our commitment in providing professional excellence.

Respect:

-Treat every person with kindness.

-Value and recognise each employee for their unique skills, talent and contribution to the company.

-Treat others as you wish to be treated.

-Listen to other people's ideas in a respectful manner.

\section{SWOT Analysis}

Strengths:

-Lack of direct competitors.

-Market research shows a huge demand for a product such as 'Auti' and what its vision aspires to be.

-Initial testing of 'Auti' has indicated great potential for example 'Auti' seemed to gain a majority of children with autism attention while they were playing with the toy. 
Page 62 of 97

-Founder is determinate and committed to make a positive difference in the autism market which will help build a caring brand image.

-All work that has been done on 'Auti' this year has been kept secret within the team, all team members have signed a confidentiality agreement.

Weaknesses:

-Lack of funding

-Current product is not patentable.

-No current presence in the US market.

-No current advisory group.

-The current name 'Auti' is seen as offensive by a majority of potential customers. "I find the name offensive as more emphasis is put on the disease rather than the child".

- The overall vision for 'Auti' is to be a therapeutic tool this makes it a medical device therefore a lot of requirements, regulations are needed especially with testing the toy.

- Difficult finding willing test subjects due to the fact that parents are very protective of their children and are cautious of exposing their child to something that could harm them, therefore a lot of time is needed to build a good reputation in order to gain parents trust.

Opportunity:

-Opportunity to develop a range of products that could be used as tools for different types of therapy.

-Creating a less complicated version of 'Auti', could help us enter the market faster.

-Market research shows that 'Auti 'could also tap into other markets but still make a positive change in the autism market for example by being a type of respite care or by acting as a transitioning tool, helping children with autism transition from home to school (Sending my autistic son to preschool, 
Page 63 of 97

2009). As both options are not classified as a medical device, this will make entering the market easier.

-First mover advantage "First into the market gains competitive advantage" (First-Mover advantage, 2013).

-Initial testing shows that 'Auti's movement is the main aspect of the toy that intrigues a majority of children who have played with it. The shape, design, and texture of 'Auti' do not seem to be as important therefore this allows us to look into redesigning 'Auti. Having a new design that has not been exposed to the public could gain a patent.

-Potential to get a patent for 'Auti's' sequence of movements.

Threat:

-Another company entering the market with a similar product before us.

-Copy cats.

- Testing concludes that 'Auti' do not teach children with autism positive behaviour.

\section{Business Growth Plan}

Our current position leads us to select the following business growth plan. Firstly we are lacking essential resources to set up shop by ourselves such as funding and human capital .Secondly we are based in New Zealand .The New Zealand autism market is not large enough for us to scale. One in hundred people in New Zealand have autism (Autism New Zealand, 2013). Therefore we needed to look into entering the international market.

We choose to enter the US market for the following reasons:

Economic environment analysis:

- Although ABA Therapy is highly demanded by parents with autistic children there are a few challenges. Therapists are very pricey they charge around $\$ 50-\$ 60$ per hour on average. Most public schools do not offer ABA. Most Insurance will not cover ABA as they consider it experimental. (How much is aba therapy, 2012). Because of the above reasons many parents 
of children with autism are learning $A B A$ themselves and practising $A B A$ therapy on their child at home. A parent can learn the basics of ABA by themselves through online tutorials or by doing a small number of workshops. Parents are not experienced therapist therefore they are always looking for tools that can help assist them with ABA therapy.

Sociocultural environment:

- The New Zealand 'Applied Behaviour Therapy' market was not big enough for the purpose of a sustainable business. This is due to the fact that many New Zealand parents and even therapist seem to view $A B A$ in a negative light. This view is probably reflective of the old $A B A$ practises which were very strict .On the other hand the US has a huge ABA therapy market. ABA therapy is one of the most common and successful therapy's for children with autism (Newman \& Hammond, 2005).

- Internationally, many parents are suspicious of robotic toys and doubt their ability to help, teach, develop and assist a child with disabilities. However some countries are more accepting of robotic toys due to the particular culture and this significantly influences how accepting and wiling parents are to try robotic toys. According to Hofstede culture dimensions the US is ranked low in uncertainty avoidance which means the US is open to trying new things such as new technologies and methods of doing things (Hofstede's cultural dimensions, 2013).

- The US is also an Individualistic and low context culture with a Monochronic time view just like New Zealand. Cultures with a Monochronic time view value time and focus on one thing at a time (Hall, 1990). These similarities reduce culture clash and make conducting business simpler.

Technological environment:

- The US is ranked number one in the world for robotic companies and research, It also has the largest national robot market and is predicted to continue being the leader in the year 2016 (World robots, 2013).

- The US is one of the top innovative countries in the world, the latest technologies we can access can help us create innovative products and sustain competitive advantage.

US market entry mode: 
We plan to enter the US market by creating a joint venture with a US company. We selected this entry mode as it would allow us to enter the US market without losing a lot of control and would allow us to gain resources which we lack (Wolf, 2000).

Creating a joint venture with a start-up rather than an established company would give us more leverage in terms of control and share allocation as the resource we bring to the venture will be more of value (Access your options for growth, 2013).

Our aim is to join venture with a start-up called Interbots who specialise in creating interactive toys, they are the creators of Popchilla our main competitor. Three main reasons lead us to choose Interbots 1) we are lacking technological skills to produce a sound sensor for Auti. Interbots are experienced in creating sound sensor technology for robotics (2) Interbots have experience and connections in the US autism market. They are partners with 'The Barber National Institute' who are working on a research project to evaluate the effectiveness of using robots in clinical therapy for treatment of children with autism, Popchilla is being used within these trials. We could benefit from partnering with Interbots as Auti could also be used in the research trails which could help validate Auti's technology' and help with Auti's development. The Barber National Institute is well recognized and respect having their approval for Auti will help us be accepted by our target market. 3) Interbots have built an initial caring brand image in the autism market which is aligned to the brand image Auti is trying to build.

It would be difficult to create a joint venture with a start-up company that has no experience in the autism market because the autism market is very sensitive and start-ups tend to avoid markets that they have no experience in as a different business approach is needed to enter these markets than less sensitive markets (Llopia, 2013).

Region of initial focus:

As we do not have the resource to distribute nationwide immediately we need to focus on a specific area in the US that would allow us to build our brand image and generate revenue to grow and gain awareness. We initially plan to target California because ABA therapy is not covered in many states in the US although in California the governor Jerry Brown has signed senate bill 126, which extends the benefits of the California autism insurance mandate through till January 1, 2017.Plans provide coverage for ABA therapy, therefore there are more ABA therapists (Autism insurance mandate, 2013). 
Page 66 of 97

\section{Target Market:}

There are a number of customer segments which 'Auti' could target if the final product proves to teach children with autism positive behaviour as marketing research has identify that a number of segments face a problem surrounding children with autism and their difficulties with learning positive behaviour. Below is a list of these segments and a detailed explanation of the problem they are facing which 'Auti' could help solve.

1. ABA Therapists:

Problem:

Lack of tools that assist applied behaviour therapy ( $A B A)$ therapist teach children with autism positive behaviour.

Impact:

More time and effort is needed to teach children with autism positive behaviour.

Solution:

A toy which assists therapists with ABA therapy.

Benefit:

A faster more efficient way to teach positive behaviour to children with autism which results in happier customers as well as happier therapist who feel that there time is better spent.

2. Parents

Problem:

ABA therapy is expensive and many parents prefer to conduct $A B A$ therapy on their child at home as this is a more affordable option. Parents are less experienced then qualified therapists therefore they need more tools that can help assist them with conducting ABA at home. One of the main reason parents with autistic children use ABA therapy is to try help their child learn positive behaviour. 
Page 67 of 97

Impact:

Parents are not providing the best ABA therapy for their child at home.

Solution:

Interactive toy that assists parents with ABA therapy.

Benefit:

Parents are providing their child the best ABA therapy they can at home.

3. Education

Problem:

Teachers have indicated that many of their students with autism do not act socially appropriate and find it hard to interact in ways that other children can relate to. Regularly methods that teachers use to teach positive behaviour to children without autism do not work on children with autism .Therefore teachers find it difficult to teach a child with autism and help them fit in better with classmates.

Impact:

Their students with autism feel left out in the classroom.

Solution:

A toy specified for children with autism that builds social skills by teaching them to distinguish between positive and negative behaviour.

Benefit:

Teachers will be able to teach their students with autism positive behaviour thus helping them learn social skills which will help them fit in with other children in the classroom.

Although there are various different segments that we could target as mentioned above, due to lack of resources we cannot target them all at once, a better growth strategy is to identify the best fit segment and target it. Our market research showed that ABA therapists and parents of children with 
Page 68 of 97

autism faced the same problem therefore our initial strategy is to promote Auti to both these segments as a tool to assist with ABA therapy this way we would be targeting two segments with one promotional tactic. We have established a number of promotional strategies to attract customers.

\section{Tactical promotion plan (Acquiring customers)}

- Establishing a joint venture with 'Interbots' who have sustained a relationship with our target market in the US will expose us to those customers raising our awareness.

- Building a strong reputation within the autism community. A majority of parents of children with autism rely on the approval and recommendation of toys specified for children with autism before they would consider purchasing.

- Our market research has identified parents of children with autism value customisation as a key feature in any toy that they would purchase for their child. Our site will have a feature which will allow users to customise 'Auti'.

- Our website will act as a social network which will help build our user base.

- We plan to communicate our products through two toy rating website which our target markets have indicated they use as sources to find toys for children with autism. 1) www.ableplay.org that provides information on toys for children with special needs, including autism. All products are evaluated by the 'National Lekotek Center' and have their own rating system 2) www.parents-choice.org the parents' choice award seals are internationally recognized and respected icons of quality.

- Our choice to target California was also a strategically promotional plan. Many rich and famous people are located in this region who have children with autism (Buchen,2011)if we are able to get 'Auti' in front of this audience we could later use celebrities as ambassadors to share their own stories of how 'Auti' helped their child. Using a celebrity will allow us to reach a wide audience and gain trust as people trust their favourite celebrity.

\section{Customer retention}

- Taking a sensitive approach to a sensitive market such as the autism market by doing such things as taking the time to prepare and approach the market in a respectful and nonoffensive manner helps build an overall caring image which will help gain customer loyalty. 
- Part of creating a caring brand image is making customers feel important (Campling, 2008).We want to connect with our customers, be part of their journey. Our website will allow users to share their child's progress.

- Each child is unique therefore a lot of emphasis will be put on customising recommendations of future products. We will track a child's progress by staying involved which will allow us to make best fitted recommendations.

- Our website will have a blog section to share the latest research, facts and interesting articles surrounding autism.

- Therapies for children with autism can be very expensive therefore we want to regularly give away vouchers for such services.

- Parents with autistic children often find it hard to cope on their own (Stresses on Families, 2000). We want to assign an individual from our team who a parent can contact if they have any questions relating to 'Auti, this builds on our caring brand image.

- Build and sustain a strong customer service team.

\section{Future Product potential}

- Our overall aim is to become a sustainable business which provides tools for various therapy sessions specifically for people with autism both children and adults. Currently 'Auti' targets ABA therapy, future products will target Cognitive behavioural therapy, Occupational therapy and Speech therapy.

- We later plan to integrate software into 'Auti'.For each toy the type of software integrated will depend on a child's age and autism type .As the child grows or progresses parents can purchase software upgrades.

- Game apps that can be connected to the physical 'Auti' with either an iPad or smartphone .These apps will teach positive behavior for example if a child conducts negative behavior in a game 'Auti' will automatically shutdown to reinforce that this is a negative behavior alternatively if the child does a positive behavior in a game 'Auti' will reinforce that the child's behavior is positive by dancing.

\section{Business Model}

- Direct sales of 'Auti'.

- Independently selling changeable covers for 'Auti's' main shell (different textures/ colours). 
"The above points can be purchased either via our online store/website or through distributers such as 'PlayAbility' who sell toys for children with disabilities through their online store as well as various retail stores throughout the US.

- Selling app games through the app store.

- Selling software upgrades for 'Auti' through our online store as features will need to be selected through our site.

\section{Strategic alliances:}

- Partnership with 'Interbots'

Partnering with 'Interbots' would give us the following advantages:

- Eliminates Popchilla as competition.

-Allow us to gain access to sound sensing technology.

-Gain a partner that already has experience with creating toys for children with autism.

-Access to their resource and expertise.

-Access to their customers and contacts.

-Reduce set up cost in the US.

How 'Interbots' would benefit from us:

- Gives them a greater product range. The more range of products a company has the better chance they have of getting into retail stores (Inventors journal, 2011).

- Eliminates us as a competitor.

- If we are later able to gain a patent for the sequence movements of 'Auti' they will also have access to this technology. 
Page 71 of 97

-Using robotics to assist therapists in therapy sessions is very new therefore the more human capital there is in a company that all believe in the same vision increases the chances of turning that vision into reality.

- Creating a partnership with therapists that work with children with autism.

Creating a partnership with therapists would give us the following advantages:

-Help communicate our products to potential customers such as parents looking for tools to help assist them with $A B A$ therapy at home.

- Potential customers feel more comfortable purchasing a product that was recommended to them by a therapist.

How therapists would benefit from us:

-They would get discounts on our products.

-We would advertise their practice on our site.

-We would recommend therapists to our customers.

\section{Barriers to entry}

- By acting fast and being the first to enter the market will make it difficult for other firms to compete. Our goal is to establish and maintain a trustworthy, caring brand thus generating loyal customers. Continuously thinking up ways to improve our technology for example updating the software inside 'Auti' through new innovative features will also help us stay ahead of any competitors.

- Sensitive markets such as the autism market are less competitive due to barriers such as rigorous testing requirements and because of the effort that must be exhausted to maintain sensitivity.

17. Market analysis:

Children with Autism: 
Autism spectrum disorder is a development disorder that often affects social abilities. (Anderson, 2013).Children with autism find it hard to distinguish between positive and negative behaviours, they often are not aware of the consequences of their actions.(Behaviour difficulties, 2007). Children with autism learn differently to other children, this includes learning positive behaviours. A new study made at 'Hopkins' university found that children with autism seem to rely more on their own internal sense of body position rather than visual information as other children do. The study concluded that the more a child does this the greater is the child's impairment in certain social and motor skills. Motor skill is a learned sequence of movements that combine to produce a smooth, efficient action in order to master a particular task. A child must have many opportunities to physically explore the surrounding in order to develop motor skills. Children with autism find it harder to learn motor skills than other children due to the fact that autism is associated with brain abnormalities which are linked to the learning of motor actions. By determining how uniquely autistic children learn, new methods can be found for treating children with autism, if this is done early enough this could help improve positive behaviours because the brain systems critical to forming internal models of behaviour that guide our actions are also critical to developing an understanding of the meaning of those actions (Different ways Autistic children Learn, 2013).

Technology and Autism:

Robot toys and other technologies such as apps have the potential to be useful tools for children with autism as they find it hard to communicate and socialise with humans, human interaction are unpredictable which can be very overwhelming to any child let alone a child with autism.

Technologies are programmed which makes them more predictable and easy to understand thus making it easier for a child with autism to process information given to them through technological devices. It has been observed that many children with autism are drawn to technology. There are mixed opinions towards technologies used as tools to teach children with autism behaviour .Haifa University Professor Tamar Weiss, a leading expert on the use of technology in autism research, said, in a 'Times of Israel article "kids are attracted to technology. Computer devices like iPads can appear to help draw autistic kids out of their shell, but sometimes that attraction is not good. Kids with autism ignore social interactions, so they often feel comfortable with computers, because using them is a singular activity. They can sit with an iPad for a whole day."(Why use Robots, 2013).

Robots used as a teaching tool for children with Autism: 
Page 73 of 97

Studies by lead scientist are showing that robot toys can help autistic children learn behaviour and social skills which they lack. In a study led by Dr Kerstin Dautenhahn and lain Werry of the University of Hertfordshire fifteen autistic children aged between five and fifteen were given a robotic toy to play with for two weeks. They concluded that each child had some kind of social interaction with the doll. The same scientists also did an earlier study with eighteen children, half of the children played with a robotic truck and the other half interacted with a non-robotic truck. Those children who played with the robotic truck began to communicating with one another (Robot-human Interactions, 2002).

Currently not enough research has been conducted to fully prove the effects of children with autism playing with robotics, although if more trials prove what the current research has shown then robot toys may revolutionise how children with autism learn positive behaviour. Robots would allow children with autism to learn social and behavioural skills for themselves. Currently such skills are taught to children with autism by a human only with limited success (Doll new cure for Autism, 2012)

Therapists use Robotics and other technologies as teaching tools.

A study conducted on nineteen children with autism while they visited a therapist by researcher Joshua Diehl, an assistant professor of psychology at the University of Notre Dame in Indiana, found that a child would do better at a therapy session if the session included a robot toy. It showed that children which attended a therapy session with a robot picked up better social skills for example making conversational comments (Behaviour difficulties,2007). Although there have been a number of studies that have shown these positive results of using a robot toy in therapy sessions with children with autism there is still a lack of research to back this up. Further research is needed to determine whether all children with autism will benefit from a robot toy or only certain children. It is important to remember that there cannot be any one specific technology that will work for every child with autism, every child is an individual thus technology needs to have the ability to be customised.

Statistics on children with autism in the US:

In a study done in 2009 it was recorded that one in eighty eight children had autism in the US. The latest statistic from the US disease control and prevention tells us that in the year 2013 on average 
around one in fifty children have autism in the US (Mercola, 2013). Health officials have concluded the fast growth rate is due to better identification of cases throughout the US due to better screening and diagnosis (Autism in the US, 2013).Although experts have identified the sources behind growth they are still not sure what the main source behind the significant growth is.

Applied Behaviour Analysis (ABA) Therapy:

Through decades of research, the field of behaviour analysis has developed many techniques for increasing useful behaviours and reducing those that may interfere with learning. $A B A$ is the use of these techniques to bring about positive change in behaviour.

Many toys and tools are used in ABA therapy for example lollies are used to reward children for positive behaviour. If a child shows positive behaviour they are rewarded with a lolly indicating to the child that their behaviour is positive (Newman and Hammond 2005).

How 'Auti' fits in with this Therapy: Auti is designed to seize responding to any loud sounds or inappropriate actions that a child with autism is sometimes prone to, for example if the child screams or hits the toy, Auti stops moving indicating to the child that their behaviour is negative. As the child begins to play appropriately, i.e. gentle stroking and speaking in a soft voice, the toy will resume motion indicating to the child that the behaviour they are now displaying is positive and therefore worthy of interaction. The rewarding aspect of the toy makes Auti a great fit for 'ABA' therapy.

\section{Market Research:}

Primary research: Overall we talked to fifteen parents and twenty therapists to help get an insight into our target markets, which proved to us that the problem that 'Auti' is trying to solve is important. After talking to parents of children with autism we identified an additional problem that they were facing in the autism market. Parents had indicated that the lack of 'respite care' available to them was a problem .Fourteen out of fifteen parents with a child who has autism which we spoke to said that they were less than moderately happy with the respite care available to them. "Respite care is temporary institutional care of a sick, elderly, or disabled person, providing relief for their usual carer"(Respite care Definition, 2013). Secondary research had also indicated that this was a problem. A recent study in the US looked into the resources and services available for treating autism. The study was done through the distribution of 1,500 surveys throughout the US. $26 \%$ were 
generally happy. Surprising even those who were generally happy with the services and resources indicated that they were unhappy with the respite services (Best Places to Live if You have Autism,2013). How Auti would fit into this market, is it would keep the attention of a child with autism for a least an hour therefore the parent could take a small break.

Our research into the autism market found a second additional problem that Auti help could fix. Children find it hard to transition into new surrounding from their home such as schools it takes an autistic child more time to adjust. Parents have said the more tools that are available to help the transition the easier it is for a child with autism. Many parents of a child with autism say a toy their child likes can make the transition better (Sending my autistic son to preschool, 2009).

How 'Auti' could help this problem? 'Auti' can act as a tool that helps a child transit and adapt into an environment such as school. "Remember, part of autism is their difficulty in dealing with changes".

Both options would be a better fit for 'Auti' at this stage due to the fact that they are not medical therefore not as much loopholes and testing will be needed before a minimum viable product can be released into the market. If we were to look into these two markets our strategy would be to enter the New Zealand market first .The New Zealand market is ideal for testing new products due its isolation from other countries therefore there is not much risk of a competitor copying your product.

From a legal standpoint, the upside to addressing a slightly different market demand is that for the purpose of a toy that can be used as a type of respite care or as a transition tool an entirely new design can be created and thus registered.

In addition to talking to our target market we also talked to five family and friends, ten teachers and five caregivers of children with autisms.

\section{Competitor Analysis:}

Currently in the market there is no product such as Auti. If Auti proves to work it will be the first robotic toy that helps teach children with autism positive behaviour. Although there are a number of indirect competitors, other robotics that help children with autism develop. Indirect competitors are listed below:

1. Robot: Ask Nao Direct: robots that teach behaviour to children with autism. 
Page 76 of 97

-Company: Humanoid robotics provider aldebaran robotics

-Benefit: Help autistic kids develop social and learning skills

-Price: NAO robot $(\$ 16,999$ US per unit).

2. Robot: Koule cool smart ball.

-Company: Created by Dr Tamie Slater, developed from a research she did when doing her PHD in robotics.

- Benefit: Help autistic kids learn emotional skills and encourage active play.

-Price: Not yet in market.

3. Robot: Popchilla

-Company: Interbots.

- Benefit: Help autistic kids learn emotional skills and encourage active play .

-Price: Not yet in market.

4. Product: My Keepon

-Company: My Keepon

-Benefit: Teaches children with autism communication skills.

-Price: $\$ 50.00$ US 


\section{References:}

ABA (2013). Retrieved April 2nd 2013 from http://www.autismspeaks.org/whatautism/treatment/applied-behavior-analysis-aba

Access your options for growth. (2013). Retrieved September 8th 2013 from http://www.infoentrepreneurs.org/en/guides/assess-your-options-for-growth/

Autism insurance mandate extension signed by Governor Jerry Brown. (2013, October 10th). Retrieved September 8th 2013 from

http://article.wn.com/view/2013/10/10/Autism_insurance_mandate_extension_signed_by_Govern or_Jerry」

Autism in the US (2013) Retrieved May 4th 2013 from

http://www.medicalnewstoday.com/articles/257959.php

Autism New Zealand. (2013) Retrieved July 8 2013 from

http://www.schoolnews.co.nz/education/295-student-support/1105-autism-spectrum-disorder-aninvisible-disability

Behaviour difficulties (2007). Retrieved November 4th 2013 from http://www.supernanny.co.uk/Advice/-/Health-and-Development/-/Special-Needs/Behaviour-andDiscipline-issues-for-children-with-Autistic-Spectrum-Disorders.aspx

Best Places to Live if you have Autism (2013) Retrieved April 11th 2013 from http://www.autismspeaks.org/about-us/press-releases/10-best-places-live-if-you-have-autism Buchen, L. (2011, November) Scientists and autism. Retrieved September 15th 2013 from http://www.nature.com/news/2011/111102/full/479025a.html

Business strategies. (2013).Retrieved July 12th, 2013 from http://www.businessplanadvice.com/strategies.asp Campling, P. W. (2008). Management: 3rd Asia Pacific Edition. Queensland: Wiley. Dautenhahn, K., Werry, I. (2002). A Quantitative technique for analysing robot-human 
Page 78 of 97

interactions. International Conference on Intelligent Robots and Systems: Lausanne, 1132-1138.

Doll new cure for Autism (2012) Retrieved April 16th 2013 from

http://www.dailymail.co.uk/health/article-147262/Could-playing-doll-new-cure-autism.html

Hall, E.T. (1990) the hidden dimension. Published by Anchor.

Heasley, S (2013, April 8th) Respite care impact. Retrieved April 11th 2013 from

http://www.disabilityscoop.com/2013/04/08/respite-care-autism-parents/17659/

Hofstede's cultural dimensions. (2013). Retrieved March $8^{\text {th }} 2013$ from http://geert-

hofstede.com/dimensions.html

How much is ABA therapy. (2012). Retrieved August 12th 2013 from

http://community.babycenter.com/post/a32001509/how_much_is_aba_therapy

Impact for Autism parents http://www.disabilityscoop.com/2013/04/08/respite-care-autismparents/17659/

Interbots partnership (2012). Retrieved July 4th 2013 from

http://medcitynews.com/2012/05/company-develops-robot-to-help-autistic-children-learn-socialreference-skills/

Inventors journal (2011). Retrieved April 2nd 2013 from

http://www.asktheinventors.com/invent.html

J, Anderson (2013) Imitation and Children with Autism. Retrieved November 2nd 2013 from http://www.gse.harvard.edu/news-impact/2013/04/imitation-and-children-with-autism-lauraedwards/

Llopia, G. (2013, May 13) Capturing sensitive Market Will Require More Than a Total Market Strategy. Retrieved September 8th 2013 from www.forbes.com.

Lynn, B. (1995). Building Brand Identity A Strategy for Success in a Hostile Marketplace. John, Wiley. Mercola (2013, April 2nd) CDC say. Retrieved November 4th 2013 from http://articles.mercola.com/sites/articles/archive/2013/04/02/autism-rates.aspx 
Page 79 of 97

Newman, B., Hammond, T. (2005) Straight Answers to Your ABA Programming Questions.

Norton, A (2013) Kelly the Robot Helps Kids Tackle Autism. Retrieved August 14th 2013

fromhttp://consumer.healthday.com/cognitive-and-neurological-health-information-26/autism-

news-51/kelly-the-robot-helps-kids-tackle-autism-675997.html

Pearson (2013) First mover advantage. Retrieved January $18^{\text {th }} 2013$ from

http://www.pearsoned.co.uk/Bookshop/article.asp?item=312

Product led (2013). Retrieved August $18^{\text {th }}$ from

http://www.businessdictionary.com/definition/product-led.html

Respite care Definition (2013) Retrieved April 10th 2013 from

http://www.oxforddictionaries.com/definition/english/respite-care

Sending my autistic son to preschool (2009). Retrieved September $11^{\text {th }} 2013$ from

http://www.circleofmoms.com/autismaspergerspdd-awareness/sending-my-autistic-son-to-preschool-357981

Stresses on Families (2000). Retrieved April 2nd 2013 from

http://oreilly.com/medical/autism/news/stress_family.html

Webber, S. \& Tether, C. (2007).Baseline review of Angel investment in New Zealand. Ministry of Economic Development, July, http://www.med.govt.nz/aboutus/publications/publications-bytopic/evaluation-of-government-programmes/archive/report.pdf

Why use Robots (2013). Retrieved April 18 2013 from

http://newswithtags.com/Robotics/altview-co-altview--why-use-robots-with-autisticchildren\#.UaVRakDdcVQ

Wolf, R.C. (2000) Effective international joint venture management .Printed in the United States of America. Library of congress Cataloging-in- publication data.

World robots. (2013). Retrieved August $12^{\text {th }} 2013$ from http://www.freedoniagroup.com/brochure/29xx/2950smwe.pdf Appendix C - Interview questions transcript 


\section{Appendix C - Questionnaire}

1) How would you define a 'high tech' start-up company?

2) What is your overall opinion on the angel investor industry in New Zealand?

3) In your personal opinion what benefits do angel investors bring to 'high tech' startup companies?

4) Are you a member of at least one or more official angel investment groups within New Zealand, if so please specify the angel investment groups you are a part of? (Skip to question 6 if participant answered no)

5) Within the formal angel investment groups that you are a part of please describe your view on the active angel investors within those networks?

6) In your experience what added benefits do 'high tech' start-ups with active angels gain compared with those 'high tech' start-ups with no active angels? Why do you think this is?

7) How would you categorise/define a lead investor?

8) Within the formal angel networks that you are a part of please describe the lead investor environment? (Skip this question if the participant answered no to question 3)

9) What sectors do you usually invest in? Why is this?

10) Is there any sector that you would avoid investing in? Why is this? (Skip to question 12 if the participant answered no)

11) Please specify the sectors that you would avoid investing in? 
12) With most of the deals you invest in are you an active investor? Why is this?

13) On average how many 'high tech' start-ups do you invest in annually? Why is this?

14) On average how much do you invest in a 'high tech' start up on the first round of investment? Why is this?

15) On average how much of a stake in a company would you ask for at the first round of investment in a 'high tech' start-up? Why is this?

16) If an entrepreneur was looking to approach an angel investor, what advice would you give that entrepreneur?

17) What essentials would you say a 'high tech' start-up needs to have in place before approaching an angel investor? (E.g. a detailed business plan including market research, stuff experience etc.) Why are these things important?

18) Are there any programmes/resources available to New Zealand start-ups that could help a 'high tech' start-up become more investment ready which you would recommend? Such as the escalator programme that used to be run by New Zealand Trade and Enterprise. (Skip to question 19 if the participant answered no)

19) What are the names of the programmes/resources and how would you say they help 'high -tech'start-ups become investment ready?

20) In your opinion what are the necessary steps an entrepreneur needs to do to find the best fitted angel investor for their start-up?

21) Various studies have found that when founders invest funds into their own start-up that this indicates a "signal" to angel investors of commitment and confidence in the new venture. How important is it to you that founders have invested their own money into their startup? To what extent is it important to know what they spend it on? 
Page 82 of 97

22) Past research has indicated that angel investors view lack of external funding as a sign that the founders do not have enough confidence in their ventures. How important is it to you that founders have both types of investment before you would consider investing? Why is this?

23) As most informal investors in New Zealand are hard to identify, what would you say is the best way to find these investors, and get their attention? Why is this?

24) Please describe the type of intellectual property protection you would expect a 'high tech' start-up to have in place or have the capability to access before you would consider investing ?Why is this?

25) What city do you reside in? 
Page 83 of 97

\section{Appendix D - Auti's Legal Strategy}

1. Existing Intellectual Property (IP) Protection:

a.) IP Protection that the toy does not currently have:

i) Patent:

The basic requirement for a patent in New Zealand (NZ) is that the invention must be new. Furthermore it must be useful and it requires an inventive step - something non-obvious. ${ }^{1}$ The toy was disclosed in the public domain at a non-specified exhibition prior to an application for a patent being filed. Furthermore, pictures and information were published on the internet. Therefore the invention can no longer be said to be new.

ii) Registered Design:

The necessary requirements for a valid registration are that the design must be new and original. Where a design is not new or original, it cannot be registered. A design is not new or original if it is the same as a design that had been previously registered or published. ${ }^{2}$ The toy's design was published on the internet, therefore this design is no longer new and so cannot be registered.

b.) IP Protection that the toy already has:

i) Confidentiality/Trade Secrets:

Information that can be protected by breach of confidence extends beyond commercially sensitive information and can also include general business information. ${ }^{3}$ Trade secrets are

\footnotetext{
${ }^{1}$ Patents Act 2013, s 14,

2 Designs Act 1953, s 5(2).

3 John Skinnon and John McDermott (eds) Law of Marketing in New Zealand ( $2^{\text {nd }}$ ed, Butterworths, Wellington, 2001) at 257.
} 
protectable under the legal doctrine of "breach of confidence". A trade secret is confidential information that is of commercial value, such as a particular manufacturing process. ${ }^{4}$ Since its public disclosure, the toy has been continually developed and as such new knowledge and information has accrued. Some of this knowledge and information is certainly worth keeping confidential for the time being. Therefore during the current development stage all those working on or with the toy have signed express confidentiality agreements and are thus under an obligation of confidence. In the event that any such personwere to disclose the information to another party, they could be successfully sued for breach of confidence.

\section{- Limitations:}

A third party obtaining the information can only be successfully sued if they know or ought to know that the information is being disclosed in breach of confidence. In that instance the third party will be bound by the same obligation of confidence as the original party under the obligation. ${ }^{5}$ Therefore, nothing can be done under breach of confidence in relation to the potential trade secrets if the information found itself in the hands of a third party who did not know that the information was subject to a confidentiality agreement.

Once information is in the open market or placed in the public domain, it can no longer be considered confidential ${ }^{6}$. Therefore, once the toy enters the open market, its functional features will become vulnerable to reverse engineering because at this point the toy will have entered the public domain. Therefore the confidential information relating to the newly developed functional elements in the toy, can no longer be

\footnotetext{
4 “How are Trade Secrets Protected?" World Intellectual Property Organisation <www.wipo.int>.

${ }^{5}$ Paul Sumpter Intellectual Property Law: Principles in Practice $\left(2^{\text {nd }}\right.$ ed, $\mathrm{CCH}$ New Zealand Limited, Auckland, 2013) at 310.

${ }^{6}$ Mars UK Ltd v Teknowledge Ltd (1999) 46 IPR 248.
} 
considered confidential. However the intellectual capital, such as the particular manufacturing process will remain a trade secret.

\section{ii) Copyright:}

Copyright is a mode of IP protection that is unaffected by prior public disclosure. ${ }^{7}$ Copyright is automatically acquired in NZ when one creates an original work. In the Copyright Act 1994, the word "work" is used to refer to forms of creative expression. In NZ "original" means that the work was independently created and not copied from a work that had been previously created. ${ }^{8}$

NZ copyright law categorises the output of creative expression. There are three categories which are potentially applicable to the toy. The first is: "industrially applied artistic work". The time span of copyright protection under this category is sixteen years from the date when more than fifty copies of the work have been made in three dimensions for the purpose of sale or hire. ${ }^{9}$

The second potential category is: "work of artistic craftsmanship". It is far less likely that toy can be categorised as such. However it would be favourable as this type of copyright lasts for 25 years from the time when the work was made. ${ }^{10}$

${ }^{7}$ Sumpter, above $\mathrm{n} 5$, at 12.

${ }^{8}$ Copyright Act 1994, s 14.

${ }^{9}$ Copyright Act 1994, s 75(4)(a).

${ }^{10}$ Copyright Act 1994, s 75(1)(c). 
Page 86 of 97

The third category will be applicable to the toy once the proposed software is created. In NZ, computer programs are included in the definition of literary works. ${ }^{11}$

\section{- Limitations:}

NZ has one of the lowest thresholds in the world for originality. Few other countries offer protection for industrially applied artistic work. The United States of America (US) has been identified as a potential target market for the toy outside of NZ. Copyright is almost always unobtainable in the US when it comes to industrial designs. ${ }^{12}$ This is because US copyright law excludes from protection designs that are used for useful articles and that are not identifiable separately from, or cannot exist independently of, the utilitarian aspects as a work of art. ${ }^{13}$ A design will be considered conceptually separable from the utilitarian aspects of the work, where it can be successfully shown that the elements of the design reflect the designer's artistic judgement, which was exercised independently of any functional considerations. ${ }^{14}$ It will be very hard to establish that any features of the toy's design reflected the designer's artistic judgment independently of functional considerations. This is because the elements of the toy have been designed in a particular way to reflect a practical purpose. Therefore it is

${ }^{11}$ Sumpter, above $\mathrm{n} 5$, at 11 .

12 Lena Schickl "Protection of industrial designs in the US and in the EU: Different concepts or different labels?" (LLM Dissertation, University of Washington, 2012) at 16.

${ }^{13}$ Copyright Act 17 U.S.C. $\S 101$.

${ }^{14}$ Brandir International Inc. v Cascade Pacific Lumber Co 834 F 2d 1142 (2d Cir 1987) at 1145. 
Page 87 of 97

very likely that it will be necessary to obtain a US design patent, if the toy's design is to be protected in the US.

Copyright protection does not prohibit reverse engineering. Everyone who uses the work as per its intended purpose is free to analyse the format and the different components that make up the work. ${ }^{15}$ The rationale behind this is the idea/expression dichotomy: copyright protects the expression of an idea and not the idea itself. The functional features of a work are not protected by copyright as that would mean extending the protection to the idea itself. For example, NZ copyright law explicitly permits decompilation of software.$^{16}$ In the US case of Atari Games Corp v Nintendo of America Inc it was also held to be a fair use. $^{17}$

iii) Layout Designs Act:

The Layout Designs Act 1994 provides protection for owners of integrated circuits and layout designs. This protection mode is similar to copyright as it is also automatically acquired provided that the originality threshold is met. The Act states that in order for the design to be original it must have been produced as the result of an intellectual effort by the maker. The layout design cannot have been commonplace at the time it was made. ${ }^{18}$ The toy has integrated circuits within its internal

${ }^{15}$ Sumpter, above n 5, at 21.

${ }^{16}$ Copyright Act 1994, s 80A(1).

${ }^{17}$ Atari Games Corp v Nintendo of America Inc. 975 F.2d 832 (Fed. Cir. 1992).

${ }^{18}$ Layout Designs Act 1994, s 6. 
Page 88 of 97

mechanisms. These circuits are laid out in a manner that is unlikely to be deemed commonplace as the functions which they dictate appear to be original.

The exclusive rights provided for the owner by virtue of the Layout Designs Act 1994 are: the right to exploit the layout design commercially as well as the exclusive right to make an integrated circuit in accordance with that layout design. ${ }^{19}$

Protection applies in NZ and other eligible countries. ${ }^{20}$ Eligible countries are those that are party to the Agreement on Trade-Related Aspects of Intellectual Property Rights (TRIPS agreement). The same protection can be acquired in the US under the Semiconductor Chip Protection Act $1984 .{ }^{21}$

\section{- Limitations:}

Reverse engineering, although not termed as such is listed as a fair use right in the Layout Designs Act 1994. ${ }^{22}$

A person will not be in breach of the owner's exclusive right to commercial exploitation if at the time of acquiring the unauthorised integrated circuit they were unaware and could not have been reasonably expected to know that the integrated circuit was unauthorised. ${ }^{23}$

${ }^{19}$ Layout Designs Act 1994, s 13.

${ }^{20}$ Layout Designs Act 1994, s 13.

${ }^{21}$ Susy Frankel Intellectual Property in New Zealand (LexisNexis, Wellington, 2011) at 812.

${ }^{22}$ Layout Designs Act 1994, s 18.

${ }^{23}$ Layout Designs Act 1994, s 15(1). 


\section{Future Strategy:}

\section{a.) Unregistered Trade Mark:}

In the event that the toy enters the marketplace prior to a trade mark being registered, protection may be acquired in NZ once sufficient goodwill is generated. The focus point of a passing off action is reputation. Reputation is established where it is shown that consumers have been conditioned into associating a mark with the goods or service of a particular source. Such conditioning occurs when the consumer is significantly exposed to the mark over time through promotion and sales. ${ }^{24}$ However significant consumer exposure essentially suggests that a sufficient amount of time must pass before the necessary goodwill is generated in the unregistered mark.

However in the meantime it may be possible for the unregistered mark to acquire protection under the Fair Trading Act 1986. The provision which is most prominent and relevant to trade marks is s 9. It reads: "No person shall in trade engage in conduct that is misleading or deceptive or is likely to mislead or deceive". A trader is able to enforce s 9 against a competitor without having to prove their own goodwill or reputation. This is because the section is concerned with consumer protection. Therefore if the consumer is being misled or deceived, that will be enough for enforcement of the section..$^{25}$

\section{- Issues to think about:}

i) Before an action for passing off can be brought against a rival competitor, the aggrieved trader must first prove that they have a protectable goodwill. ${ }^{26}$ Also the fact that goodwill need not be shown under the Fair Trading Act 1986 is only a theoretical distinction. In practice evidence of reputation is nonetheless

\footnotetext{
${ }^{24}$ Sumpter, above n 5, at 194.

${ }^{25}$ Ibid, at 200.
}

${ }^{26}$ IR Commers v Muller \& Co's Margarine Itd [1901] AC 217 (HL) at 223-224. 
required in a Fair Trading Act action if there is an alleged confusion of names. ${ }^{27}$ Therefore it is certainly worth registering a trade mark since infringement becomes so much easier to prove. Instead of establishing goodwill and reputation, one need only point to the register..$^{28}$

ii) The Fair Trading Act 1986 is a NZ statute and therefore cannot be enforced in relation to overseas trade. It is also inconceivably difficult to establish passing off if the infringement occurs in another country prior to the aggrieved trader having begun trading in that country.

\section{b.) Registered Trade Mark:}

Since the plan is to potentially sell the toy in the US as well as NZ, it is advisable that a mark in the form of a name and logo is registered in both countries. The Madrid Protocol, allows applicants to file a single application for registration designating at once all the countries where protection is sought. Of course the designated countries must be members of the Madrid Protocol. ${ }^{29}$ The US and $\mathrm{NZ}$ are both members.

A registered trade mark can and should be attained for a suitable name and logo just before the toy is released into the market. Further down the line it is possible that more features could be registered as a trade mark. Shapes, colours and even smells can sometimes be registered if the trader can show sufficient evidence which demonstrates that the public understands the colour shape or smell as being a distinguishing feature of the particular trader. ${ }^{30}$ However in order to satisfy this requirement, the trader must provide convincing proof that shows that the public has actually

\footnotetext{
${ }^{27}$ Sumpter, above n 5, at 201.

${ }^{28}$ Greg Arthur and Matt Sumpter "Intellectual Property for Non-Specialists" (paper presented to New Zealand Law Society Seminar, Wellington, August 2008) at 12.

${ }^{29}$ Sumpter, above n 5, at 144.
}

${ }^{30}$ Trade Marks Act 2002, s 18(2). 
grown to associate these distinguishing features with that trader. ${ }^{31}$ Essentially if the venture turns out to be successful and the toy proves to be very popular to the extent that consumers for example recognise it by its distinguishing shape, then the shape too can be registered as the trade mark.

\section{- Issues to think about:}

i) There is a potential issue with the descriptive nature of the name. The name stems from the word autistic therefore it is arguably too descriptive and insufficiently distinctive for registration. Words or word combinations which serve to designate the kind, quality, quantity, intended purpose, value or the like of goods and services for which they are used are insufficiently distinctive for registration. ${ }^{32}$

ii) The name may be unfavourable with the target market. A trade mark may be opposed on the ground that it is likely to offend a significant section of the community. ${ }^{33}$ There is a risk that the name will be offensive to some people, particularly those in the Autism community.

\section{c.) Registered Design:}

The toy's design should be registered because US copyright law does not provide protection for industrially applied artistic work that is made for the purposes of sale and hire. Equivalent protection is provided for in the US in the form of a design patent. ${ }^{34}$ The design patent is essentially the same as a registered design in NZ. The difference is that NZ identifies registered designs as an independent

\footnotetext{
${ }^{31}$ Sumpter, above n 5, at 158.

32 Trade Marks Act 2002, s 18(1)(c).

${ }^{33}$ Trade Marks Act 2002, s 17(1)(c).
}

${ }^{34}$ Patents Act 35 U.S.C. § 173. 
mode of IP protection, whereas the US places registered designs within the scope of their Patents Act.

However the design as it existed during the public disclosure cannot be registered. Therefore it is advisable that the design be substantially changed so that it can once again be registered. The design that seeks protection must not only differ from a previous design in immaterial detail or merely through features that are common variants used in the relevant trade..$^{35}$ Fortunately the design may qualify as being substantially different if it combines some of the old features as well as some that are new. What is important is that the appearance of the design as a whole is novel. ${ }^{36}$

\section{- Issue to think about:}

i) Had the toy's design been registered prior to the public disclosure, it would have been substantially novel and thus potential competitors would have to of had significantly different designs in order to avoid infringement. However if the design is changed now, so that it is substantially different to the extent that it could once again be deemed original for the purposes of registration, it would nonetheless lose the status of being substantially novel. Therefore potential rivals would be likely to escape liability by making minor variations to the design due to the original design being in the public domain. ${ }^{37}$

Therefore in the event that it is revealed upon the conclusion of the product testing that successful interaction with the children is largely due to the toy's functional features, which is highly likely, it is advisable that the design is drastically changed to the extent that it is once again substantially novel.

\footnotetext{
35 Designs Act 1953, s 5(2).

${ }^{36}$ Sumpter, above n 5, at 295.

${ }^{37}$ Skinnon and McDermott, above n 3, at 255.
} 


\section{d.) Patent:}

A patent can be obtained in the event that new elements are developed for the toy since the public disclosure, which meet the requirements of a patentable invention. Aside from being new, these elements will also need to be useful and they require an inventive step. ${ }^{38}$

\section{- Issues to think about:}

i) The proposed software which is one of the features that was not developed at the time of the public disclosure cannot be protected under the new patent law. Even if the software turns out to be truly innovative, it cannot be protected because the Patents Act 2013 states that a patent application will be denied if the invention lies solely in the computer program..$^{39}$ However inventions which have embedded software will remain patentable. Although the planned for software will be embedded, it is still unpatentable because the toy itself cannot be patented due to the prior public disclosure.

ii) Patent law is very expensive and has to be registered in each country separately. Unless you register a patent in every single country around the world, there is the danger that a potential competitor who sees huge potential in the invention, will simply outsource and trade out of a country where you don't have a patent.

iii) Patents do not seem to be favourable with most small to medium sized manufacturing companies because they tend to see them as being an expensive protection mode that provides a limited benefit. ${ }^{40}$

\footnotetext{
38 Patents Act 2013, s 14,

${ }^{39}$ Patents Act 2013, s 11(3).

${ }^{40}$ Wesley Cohen, Richard Nelson and John Walsh “Protecting Their Intellectual Assets:

Appropriability Conditions and Why U.S. Manufacturing Firms Patent (or Not)" (NBER Working Paper
} No. 7552) at 2. 


\section{e.) Product Safety Standards:}

The Product Safety Standards (Toys) Regulations 2005 deems it necessary for toys intended for use by children who are up to 36 months of age to comply with the Standard AS/NZS ISO 8124.1:2002. Any breach of the Standard means that the regulation is also breached and this is an offence under the Fair Trading Act. ${ }^{41}$

\section{- Issues to think about:}

i) It is not possible to simply label the toy as not being suitable for children under 36 months of age. If the child is physically and intellectually capable of playing with the toy in the way it was intended to be used, then it will be deemed as a toy designed for children under 36 months of age. ${ }^{42}$ The toy is simple to use and testing with small children will likely show that they are capable of using the toy in the way in which it is meant to be used. Thus it is highly likely that the Standard will apply regardless of whether there is a minimum age label attached to it.

ii) The standard prohibits the supply of small toys or toys with small parts, which can be swallowed or inhaled by children under 36 months of age. ${ }^{43}$ Generally any toy or toy part that is smaller than a ping pong ball or a $35 \mathrm{~mm}$ film canister will be in breach of the Standard. ${ }^{44}$ The toy is large, however it contains multiple small parts on the interior. These parts are not meant to be

${ }^{41}$ Fair Trading Act 1986, s 30.

42"Children's Toys: A Guide to Complying with the Product Safety Standard" (2009) Commerce Commission New Zealand at $2<w w w . c o m c o m . g o v t . n z>$.

43 Ibid, at 1.

${ }^{44}$ Ibid, at 2. 
removable, but the Standard states that toys must not have pieces that are capable of being broken off as a result of normal use or reasonably foreseeable abuse. A reasonably foreseeable abuse test simulates conditions in which abuse could occur. For example it is reasonably foreseeable that a small child may drop the toy as they are not yet able to grip and hold onto it. ${ }^{45}$ Given the particular target market, it may be necessary to also test the toy in conditions where it is thrown, as children with Autism, are sometimes prone to such behaviour.

iii) Another potential hazard is the fur that covers the toy's exterior shell. A potential choking hazard involving fur on a toy has been identified in the past where an investigation by the Commerce Commission established that it could be swallowed as a result of it coming apart when it was being pulled, chewed or sucked. ${ }^{46}$ Therefore it will be necessary to conduct testing to ensure that the attached fur does not come away in the event that it is chewed, pulled or sucked. Alternatively it may be worth considering using a different covering material altogether.

45 “Children's Toys: A Guide to Complying with the Product Safety Standard", above n 45, at 2.

46 “Dulux Recalls Toy Dogs after Complaint to Commerce Commission” (2012) Commerce Commission New Zealand <www.comcom.govt.nz>. 


\section{Summary:}

- Existing Protection:

Confidentiality: All persons who have signed confidentiality agreements are under an obligation of confidence. Protection also extends to those that obtained information in circumstance that impart an obligation of confidence (clearly confidential situations). Protection does not extend to third parties who obtained information without the knowledge that it was disclosed in breach of confidence.

$>$ Copyright: The toy has automatically acquired copyright protection in NZ. The toy is most likely to be categorised as an industrially applied artistic work. There is no equivalent category of protection under US copyright. In the US this type of protection is obtainable under a design patent.

Layout Designs Act: Provides another automatic source of protection. This protection mode applies to the integrated circuits within the toy's internal mechanisms. Reverse engineering of these integrated circuits is a fair use under the Layout Designs Act 1994.

- Future Strategy:

Unregistered Trade Mark: an unregistered trade mark is protectable in NZ under the Fair Trading Act 1986 and under the tort action of passing off, once it can be shown that the there is goodwill associated with the mark. Goodwill is acquired through trade and sufficient publicity. Therefore usually a substantial amount of time in the market place is required before the requisite goodwill is accrued. Furthermore these methods are inappropriate for dealing with potential infringement that occurs outside of NZ. As such, it is advisable that a trade mark is registered a short time before the toy enters the market.

Registered Trade Mark: The name is potentially insufficiently distinctive and there is also the danger that it is offensive to the target market. Therefore it is advisable that a less controversial name is chosen. The Madrid Protocol, allows 
applicants to file a single application for registration designating at once all the countries where protection is sought. Therefore the name and logo should be registered in the US as well as NZ. More features such as the toy's distinct shape may possibly be registered further down the line if over time the public grows to associate such distinguishing features with the trader.

$>$ Registered Design: It advisable that the design be drastically changed so that it is once again substantially novel. If this is done the new design can be registered in NZ. It will also make it possible to acquire a Design Patent in the US.

Patent: Can be obtained for any of the newly developed features since the public disclosure, provided that these meet the requirements of a patentable invention. However it is only advisable that a patent be obtained for any such feature if it is truly an innovate invention that is worth protecting. In NZ this protection mode no longer applies to software as such, under the Patents Act 2013.

Product Safety Standards: In order to ensure compliance with the relevant safety standard, it will be necessary to conduct a series of tests. It is advisable that the toy is dropped as well as thrown to ensure that small parts, which are capable of being swallowed or inhaled are not broken off in such instances. Furthermore the fur covering the toy should be tested to see that it does not come away when being chewed, pulled or sucked as this is a recognised choking hazard. It is advisable that an alternative material is found to cover the toy's exterior shell. 